\title{
Experimental Study on Thermal Insulation Effect of the Buried Oil-Gas Pipelines in Permafrost Regions
}

\author{
Deren Liu $\mathbb{D}^{1,2}$ Jiale Yang $\mathbb{D}^{1,3}{ }^{1,3}$ Xu Wang, ${ }^{1,2}$ Junming Zhao, ${ }^{1}$ Shuochang $\mathrm{Xu},{ }^{1}$ \\ and Yongchun Zhao ${ }^{3}$ \\ ${ }^{1}$ School of Civil Engineering, Lanzhou Jiaotong University, Lanzhou 730070, China \\ ${ }^{2}$ National and Provincial Joint Engineering Laboratory of Road \& Bridge Disaster Prevention and Control, Lanzhou 730070, China \\ ${ }^{3}$ State Key Laboratory of Frozen Soil Engineering, Northwest Institute of Eco-Environment and Resources, Chinese Academy \\ of Sciences, Lanzhou 730000, China
}

Correspondence should be addressed to Deren Liu; liuderen@mail.lzjtu.cn

Received 11 October 2021; Revised 15 November 2021; Accepted 9 December 2021; Published 4 January 2022

Academic Editor: Qingzhi Wang

Copyright (c) 2022 Deren Liu et al. This is an open access article distributed under the Creative Commons Attribution License, which permits unrestricted use, distribution, and reproduction in any medium, provided the original work is properly cited.

In permafrost regions, long distance buried pipelines are widely used to transport oil and natural gas resources. However, pipeline problems occur frequently due to the complicated surrounding environment and transportation requirement of positive temperature. In this study, a thermal insulation layer was applied to mitigate permafrost degeneration around the buried oilgas pipelines. Based on engineering background of the Sebei-Xining-Lanzhou natural gas pipeline in China, an indoor model test was designed and carried out in which many key indices, such as the temperature regime, vertical displacement, pipeline wall stress, and water content, were closely monitored. The test results indicate that the large heat loss of the buried pipeline produces a rapid increase in ground temperatures which seriously reduces the bearing capacity of the permafrost foundation. The buried oil-gas pipelines with a thermal insulation layer can effectively reduce the thawing range and vertical displacement of the permafrost foundation around the buried pipelines, so as to control the stress of the pipeline wall in the normal range and protect the safe and stable operation of the buried oil-gas pipelines. The experimental results can serve as a reference for the construction, operation, and maintenance of buried oil-gas pipelines in permafrost regions.

\section{Introduction}

Permafrost is defined as ground (soil or rock including ice) with a temperature at or below $0^{\circ} \mathrm{C}$ over at least two consecutive years [1]. Permafrost regions account for approximately $25 \%$ of Earth's land surface in which there are abundant oil and gas resources [2]. In recent years, the social demand for energy has further increased with the rapid development of the economy. Long distance pipelines are one of the most efficient and economical transmission ways; a large number of oil-gas pipeline projects have been built to develop and transport oil and natural gas resources in permafrost regions [3-5]. Examples include the TransAlaska (Alyeska) Pipeline System (TAPS) [6-8], the Norman Wells Oil Pipeline (NWOP) [9-11], the Russian Far East Pipeline in Siberia $[12,13]$, the Golmud-Lhasa Oil
Pipeline (GLOP) [14, 15], the Sebei-Xining-Lanzhou natural gas pipeline [16-18], and the China-Russia Crude Oil Pipeline (CRCOP) [19-26]. Up to now, the above wellknown oil-gas pipelines play an important role in the effective exploitation and utilisation of oil and gas resources in permafrost regions. However, due to the complicated surrounding environment and special transportation requirements of oil and gas, pipeline disease occurs frequently in permafrost regions.

In permafrost regions, the primary challenge of the buried oil-gas pipelines is differential frost heave and thaw settlement of frozen soil $[1,4,13,14]$, which indirectly affects the thermal stability and mechanical properties of the buried pipelines (Figure 1). In particular, frost heaving is the most serious problem that causes additional stress and large deformation of the buried pipelines. In addition, the internal 




FIGURE 1: Schematic of multicoupling model between pipeline and soil [13].

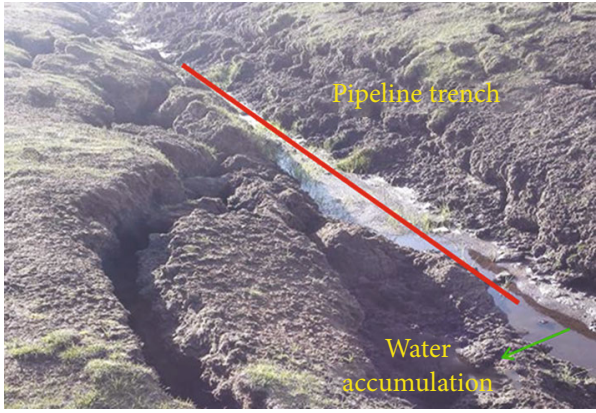

(a) Pipeline trench subsidence

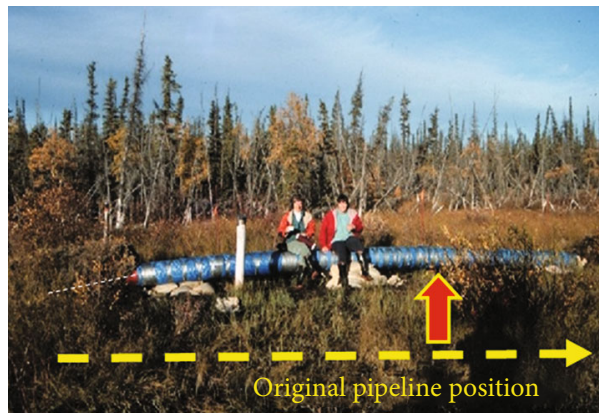

(c) Pipeline lateral buckling

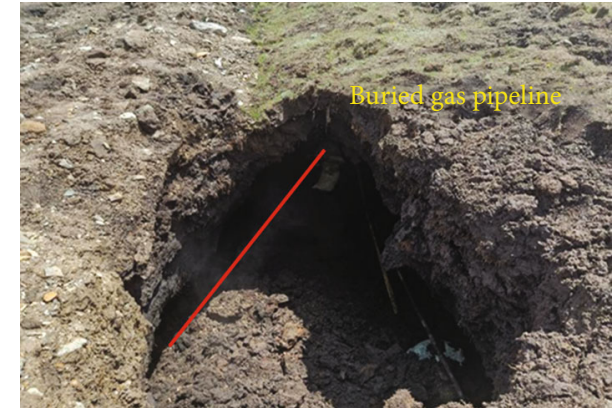

(b) Pipeline trench thaw slumping

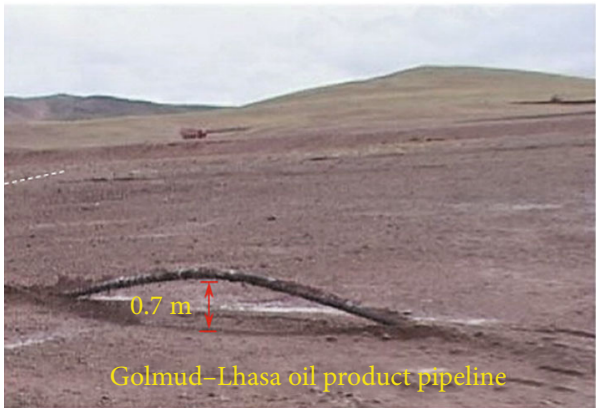

(d) Pipeline uplift deformation

FIGURE 2: Damage types of the buried oil-gas pipelines: $(\mathrm{a}, \mathrm{b})$ photoed at Laji mountain of the Sebei-Xining-Lanzhou buried gas pipeline in July 2016, (c) photoed at the Norman Wells Oil Pipeline in September 1997 [28], and (d) photoed at Wuli in June 2002 [8].

temperature of natural gas pipelines often needs to be maintained at $6^{\circ} \mathrm{C} \sim 15^{\circ} \mathrm{C}$ and that of some crude oil pipelines must be maintained at $30^{\circ} \mathrm{C}$ to ensure normal transportation. The continuous heat loss from the buried pipelines will make a rapid increase in the ground temperatures and permafrost degradation. A series of serious pipeline problems, including pipeline trench subsidence, pipeline trench thaw slumping, and frost heaving and buckling of the pipeline, are induced during the operation of the buried pipelines (Figure 2). The above adverse actions lead to large deformation, high stress concentration, and even fracture and liquid leakage of the buried oil-gas pipelines, resulting in an immeasurable loss of economic property [3, 8, 17, 27]. Therefore, it is necessary to study the complicated interaction between the buried oil-gas pipelines and the foundation soil in permafrost regions. 


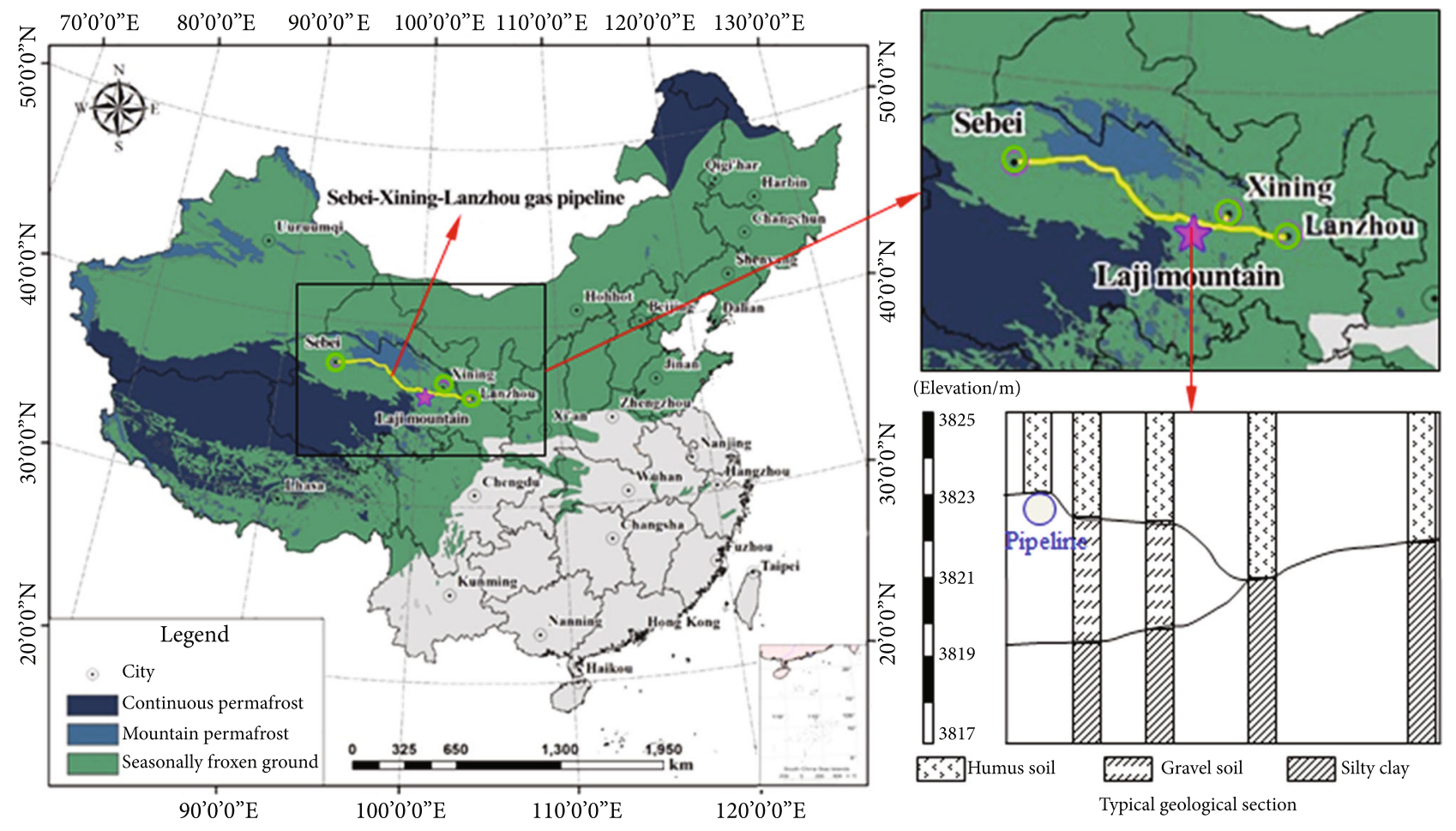

FIgUre 3: Distribution of Sebei-Xining-Lanzhou gas pipeline and location of study site.

Table 1: Specific parameters of Sebei-Xining-Lanzhou buried gas pipeline.

\begin{tabular}{|c|c|c|c|c|c|c|}
\hline Material & Pressure & Diameter & Thickness & Anticorrosion & Thermal insulation layer & Buried depth \\
\hline L415 & $6.4 \mathrm{MPa}$ & $660 \mathrm{~mm}$ & $7.1 \sim 8.7 \mathrm{~mm}$ & $3 \mathrm{PE}+$ coal tar enamel & No & $2.5 \mathrm{~m}$ \\
\hline
\end{tabular}

Note: L415: the yield strength of pipeline steel; 3PE: the three-layer anticorrosive structure $[17,18]$.

At present, a considerable amount of research has been done on the numerical simulation method and in situ investigation and observation of oil-gas pipelines in permafrost regions. Numerical calculation is mainly used to predict the long-term thermal stability of buried oil-gas pipelines [29-35]. The field investigation and observation can truly reflect in situ pipeline problems and the change trend of the permafrost table during the operation of the buried pipelines $[14,20]$. However, wall stress and deformation of the buried pipelines are difficult to monitor in field and still need to be sufficiently validated by experiments. In addition, previous experimental studies have focused on mechanical interaction of pipe-soil during freezing and thawing $[6,19$, $36,37]$. Large heat loss of the buried pipelines is often not considered in the model test, but it makes a rapid rise in the ground temperatures so that it cannot be ignored [22, 24]. Moreover, the thermal insulation effect of the buried insulated pipeline also lacks relevant test data. Consequently, it is significant to study the thermal insulation effect of the bare or insulated pipeline in permafrost regions.

In this paper, based on the actual engineering background of Sebei-Xining-Lanzhou buried natural gas transmission pipeline in China, an indoor scaled-down pipelinefoundation model test was carried out to perform experi- mental analysis on the interaction mechanism between pipeline and soil. Through the controlled trial, we verified the effectiveness of thermal insulation layer from the temperature regime of the foundation soil around the pipelines and the vertical displacement and stress variation of the buried pipelines. The experimental results can provide an important reference for the construction, operation, and maintenance of the buried oil-gas pipelines in permafrost regions.

\section{Engineering Background of the Research}

This study focuses on the Sebei-Xining-Lanzhou buried gas pipeline in China (Figure 3), which was put into operation on September 6, 2001. It enters the Loess Plateau from the mideastern of the Qinghai-Tibet Plateau and finally reaches Lanzhou, Gansu $\left(36^{\circ} \sim 38^{\circ} \mathrm{N}, 94^{\circ} \sim 103^{\circ} \mathrm{E}\right)$, with a total length of $926.6 \mathrm{~km}$. The transmission medium of the buried pipeline is positive temperature liquefied natural gas $[17,18]$, and the specific pipeline parameters are shown in Table 1.

The Sebei-Xining-Lanzhou buried gas pipeline passes through the high-elevation sporadic permafrost regions. The double effects of freeze-thaw and large heat loss of the pipeline lead to periodic subsidence and arch warping deformation of the pipeline. This problem is most obvious in the 
Laji mountain area among the whole line, which is extremely unfavourable to the safe and stable operation of the pipeline. Therefore, the study site is located in the Laji mountain area. The Laji mountain area belongs to the continental plateau climate with the characteristics of thin air, low air pressure, and low temperature. It is windy in spring, dry and snowy in winter, with annual precipitation of $300 \sim 600 \mathrm{~mm}$, and mainly concentrated in May to September. The annual total solar radiation is about $60 \sim 80 \mathrm{kal} / \mathrm{cm}^{2} \cdot \mathrm{a}$. The annual temperature difference can reach $20 \sim 25^{\circ} \mathrm{C}$, and the annual average temperature is $0 \sim-5^{\circ} \mathrm{C}$. The permafrost table is at the depth of $1.6 \sim 4.3 \mathrm{~m}$. The geotechnical survey shows that the shallow strata consist of humus soil, gravel soil, and silty clay, respectively (Figure 3 ). The humus soil belongs to icerich permafrost with a thickness of about $2.0 \sim 3.8 \mathrm{~m}$, moisture content of $40 \% \sim 180 \%$, and organic matter content of $\zeta>5 \%$. Moisture content of silty clay is $30 \% \sim 140 \%$ [16-18]. In addition, a typical section K688+600 was selected to drill holes (\#1, \#2, and \#3), arrange temperature sensors, and monitor the variation of ground temperature with depth. The \#3 hole is located $8 \mathrm{~m}$ away from the buried pipeline, which is little affected by the heat release of the gas pipeline and can be regard as a natural hole [17]. Figure 4 shows that the ground temperature is greatly affected by air temperature in the depth of $1 \mathrm{~m}$. When the depth is below $3 \mathrm{~m}$, the ground temperature varies stably from -1 to $-2^{\circ} \mathrm{C}$

\section{Materials and Methods}

3.1. Experimental Principle and Theory. In permafrost regions, frozen soil around pipelines can be considered to be homogeneous and isotropic, and only the heat conduction and ice-water phase change are considered during freeze-thaw cycles. At the same time, the axial size of the pipeline is much larger than the radial size, so the radial temperature distribution of the pipeline can be considered as a 2-dimension problem when the heat conduction of the pipeline wall is ignored. The equation of heat conduction is described as follows [38-41]:

$$
C_{e}^{*} \frac{\partial T}{\partial t}=\frac{\partial}{\partial x}\left(\lambda_{e}^{*} \frac{\partial T}{\partial x}\right)+\frac{\partial}{\partial y}\left(\lambda_{e}^{*} \frac{\partial T}{\partial y}\right)
$$

where $C_{e}^{*}$ and $\lambda_{e}^{*}$ are the equivalent volumetric heat capacity and equivalent thermal conductivity of frozen soil, respectively; $T$ is temperature; $t$ is time; and $x$ and $y$ are the distance.

Based on the similarity principle, some key parameters were controlled to simulate the in situ situation as truly as possible. According to dimensional analysis [42], we can get

$$
\frac{\lambda t}{c x^{2}}+\frac{\lambda t}{c y^{2}}=1
$$

where $\lambda t / c x^{2}$ and $\lambda t / c y^{2}$ are dimensionless terms whose corresponding similarity index $C_{\lambda} C_{t} / C_{c} C_{y}^{2}=C_{\lambda} C_{t} / C_{c} C_{x}^{2}=C_{\lambda}$ $C_{t} / C_{c} C_{l}^{2}=1$. We assume that the thermal parameters of soil

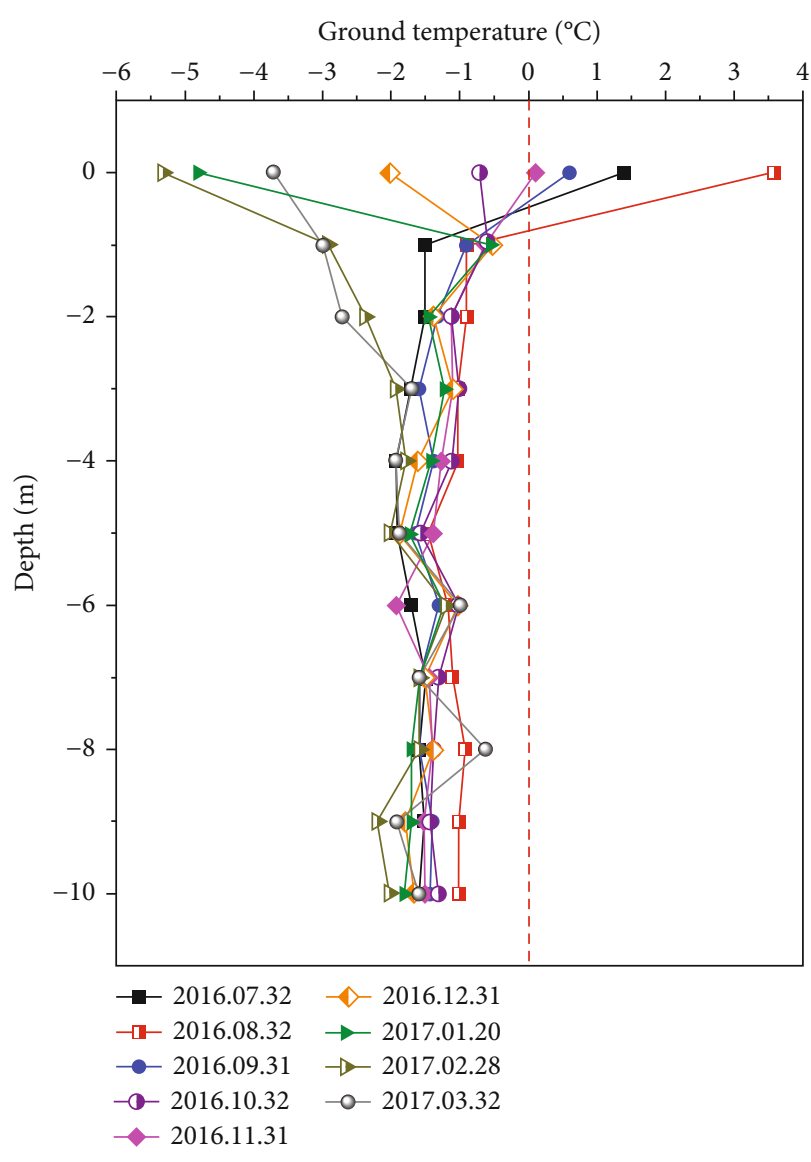

FIgURE 4: Variation of natural ground temperature with depth.

TABLe 2: Similarity ratios of the scaled model test (prototype/ model).

\begin{tabular}{lccccc}
\hline Physical variable & $C_{\lambda}$ & $C_{c}$ & $C_{t}$ & $C_{l}$ & $C_{T}$ \\
\hline Value & 1 & 1 & 60.83 & 7.8 & 1 \\
\hline
\end{tabular}

Note: $C_{\lambda}$ : thermal conductivity; $C_{c}$ : specific heat capacity; $C_{t}$ : time; $C_{l}$ : geometric dimensions; $C_{T}$ : temperature.

TABLE 3: Key physical parameters of humus soil.

\begin{tabular}{ccccccc}
\hline$G_{s}$ & $w_{\mathrm{op}}(\%)$ & $\rho_{\mathrm{d} \max }\left(\mathrm{g} / \mathrm{cm}^{3}\right)$ & $w_{P}(\%)$ & $w_{L}(\%)$ & $I_{P}$ & $k(\mathrm{~cm} / \mathrm{s})$ \\
\hline 2.16 & 55.6 & 0.88 & 52.1 & 88.0 & 35.9 & $>10^{-6}$ \\
\hline
\end{tabular}

Note: $G_{s}$ : specific gravity; $w_{\mathrm{op}}$ : optimal water content; $\rho_{\mathrm{dmax}}:$ maximum dry density; $w_{P}$ : plastic limit; $w_{L}$ : liquid limit; $I_{P}$ : plasticity index; $k$ : permeability coefficient.

in field and laboratory tests are equal [19], so the similarity index of the specific heat is $C_{c}=1$, and that of the thermal conductivity is $C_{\lambda}=1$. In this model test, the time of a freeze-thaw cycle was designed to be six days, so we can calculate the similarity ratio of time $C_{t}=t_{p} / t_{m}=365 / 6=60.83$, where $t_{p}$ is in situ time and $t_{m}$ is laboratory time. According to the known similarity indices $C_{c}, C_{\lambda}$, and $C_{t}$, we can determine the similarity ratio of geometric dimensions $C_{l}=L_{p} /$ $L_{m}=7.8$, where $L_{p}$ is the in situ geometric dimension and $L_{m}$ is the model geometric dimension. As mentioned in the 


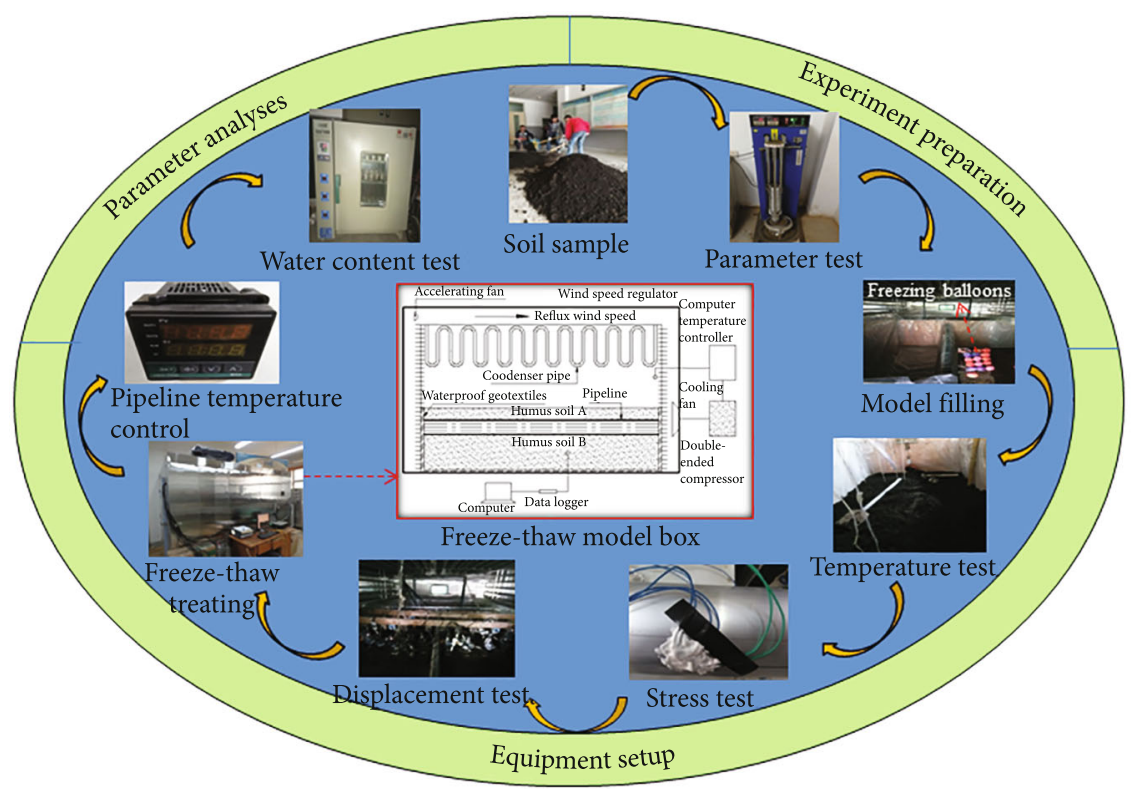

FIGURE 5: Schematic diagram of experimental equipment and procedures.

TABle 4: Specific parameters of the buried gas pipeline model.

\begin{tabular}{lcccccccc}
\hline Material & Length, $L(\mathrm{~m})$ & Diameter, $D(\mathrm{~m})$ & Thickness, $t(\mathrm{~mm})$ & Buried depth $d(\mathrm{~m})$ & $v$ & $E(\mathrm{GPa})$ & $\alpha l\left({ }^{\circ} \mathrm{C}\right)$ & {$[\sigma](\mathrm{MPa})$} \\
\hline Aluminium alloy & 2.3 & 0.08 & 1.5 & 0.27 & 0.34 & 70 & $21.65 \times 10^{-6}$ & 35 \\
\hline
\end{tabular}

Note: $v$ : Poisson's ratio; $E$ : elasticity modulus; $\alpha l$ : coefficient of linear expansion; $[\sigma]$ : allowable stress.

engineering background part, the pipeline diameter in practical engineering is $0.66 \mathrm{~m}$, so we can get the diameter of the pipeline model $L_{m}=0.085 \mathrm{~m}$, and the final selected pipeline diameter is $0.08 \mathrm{~m}$. The thickness of the pipeline wall is less than $2 \mathrm{~mm}$. The average buried depth of the Sebei-XiningLanzhou buried gas pipeline in the Laji mountain area is $2.1 \mathrm{~m}$, so we can deduce that the buried depth of the pipeline in the model test is $0.27 \mathrm{~m}$. Equation (2) shows that there is no direct connection between temperature boundary conditions $C_{T}$ and other physical parameters in the similarity theory, so the temperature boundary conditions of the model box and the pipeline model are in accordance with the actual situation $[19,42]$. The specific similarity ratios of the scaled model test are listed in Table 2.

3.2. Soil Sample. Humus soil was selected for the test soil sample and was obtained from around the gas pipeline in the Laji mountain area of Qinghai, China. Since humus soil contains many plant roots, the organic matter in the soil sample should be firstly removed before the experiment. Then, the collected soil sample was dried at $70^{\circ} \mathrm{C}$ and passed through a $5.0 \mathrm{~mm}$ sieve. Finally, according to the Chinese standard for geotechnical testing method GB/T 501232019 [43], the key physical parameters of the humus soil were measured, as shown in Table 3.

3.3. Experimental Equipment. The experimental equipment mainly consists of three parts: a freeze-thaw cycle system, a pipeline simulation system, and three data acquisition sys- tems (Figure 5). The functions and detailed parameters of these devices are as follows:

(1) Freeze-thaw cycle system: pipeline models were subjected to a full-automatic freeze-thaw machine to simulate the process of freezing and thawing periodically. The temperature controller (XT5701LTB-450) realizes real-time temperature changes by the compressor and condenser tube. The temperature range is $-40^{\circ} \mathrm{C} \sim+$ $90^{\circ} \mathrm{C}$ with an accuracy of $\pm 0.05^{\circ} \mathrm{C} \sim 0.1^{\circ} \mathrm{C}$ and resolution of $0.1^{\circ} \mathrm{C}$. The experiment parameters such as the temperature and time of the freeze-thaw cycle and cycle number could be adjusted by the central control panel

(2) Pipeline simulation system: the pipeline model and temperature intelligent controller (HBG-7411) were combined to simulate the buried oil-gas pipelines in practical engineering. By comparing the performance of different pipeline materials before the experiment, it was found that aluminium alloy was the most suitable material for the pipeline model. Based on the similarity criteria and material properties, the specific parameters of the buried gas pipeline models were summarised, as shown in Table 4 . The temperature range of the intelligent temperature controller is $-29 \sim+39^{\circ} \mathrm{C}$ with precision of $\pm 0.1^{\circ} \mathrm{C}$, which is connected with a $90 \mathrm{~W}$ resistance wire inside the centre of the pipeline model to power on and release heat to simulate the positive temperature transportation in the field 
TABLE 5: Specific parameters of the sensors and data collection devices.

\begin{tabular}{|c|c|c|c|c|c|c|}
\hline \multirow{2}{*}{ Type } & \multicolumn{2}{|c|}{ Sensor } & \multicolumn{4}{|c|}{ Date collection device } \\
\hline & Model & Range & Precision & Model & Precision & Time interval \\
\hline Temperature testing system & WPT - PT100A & $-50 \sim+300^{\circ} \mathrm{C}$ & $\pm 0.1^{\circ} \mathrm{C}$ & $\mathrm{RX}-6000 \mathrm{~F}$ & $\pm 0.2 \% \mathrm{FS}$ & $1 \mathrm{~h}$ \\
\hline Displacement testing system & $\mathrm{BQF}-350 \mathrm{~A}$ & $0 \sim 50 \mathrm{~mm}$ & $\pm 0.01 \mathrm{~mm}$ & INV2312 & $\pm 0.2 \% \mathrm{FS}$ & $1 \mathrm{~h}$ \\
\hline Stress testing system & BA $120-3 \mathrm{AA}$ & $0 \sim \frac{20000 \mu \mathrm{m}}{\mathrm{m}}$ & $2.0 \pm 1 \%$ & DH3816N & $\pm 0.5 \% \mathrm{FS}$ & $0.25 \mathrm{~h}$ \\
\hline
\end{tabular}

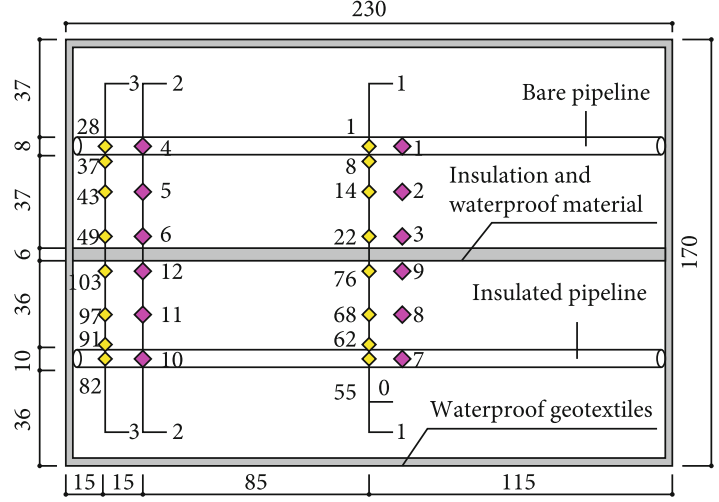

(a)

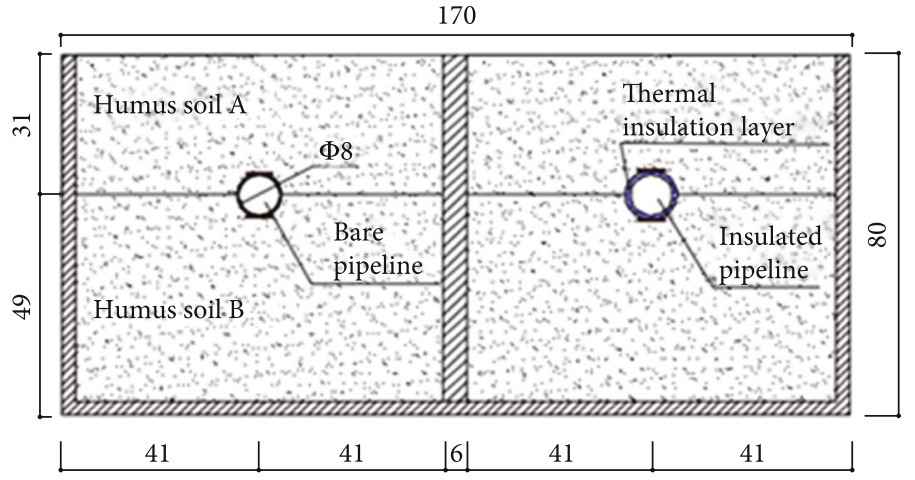

(b)

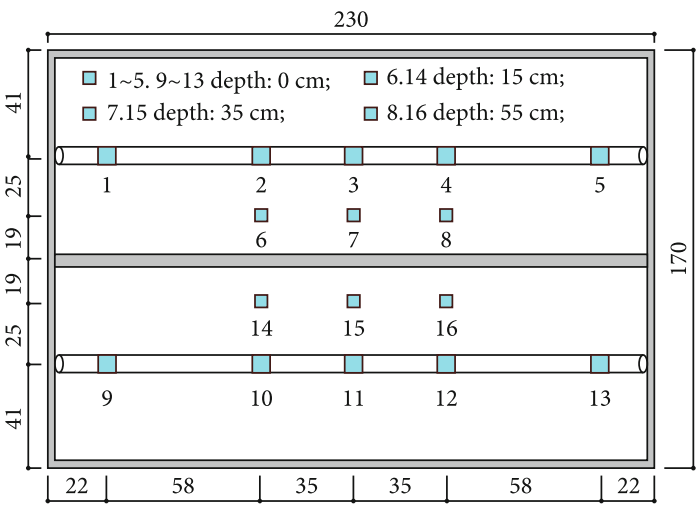

(c)

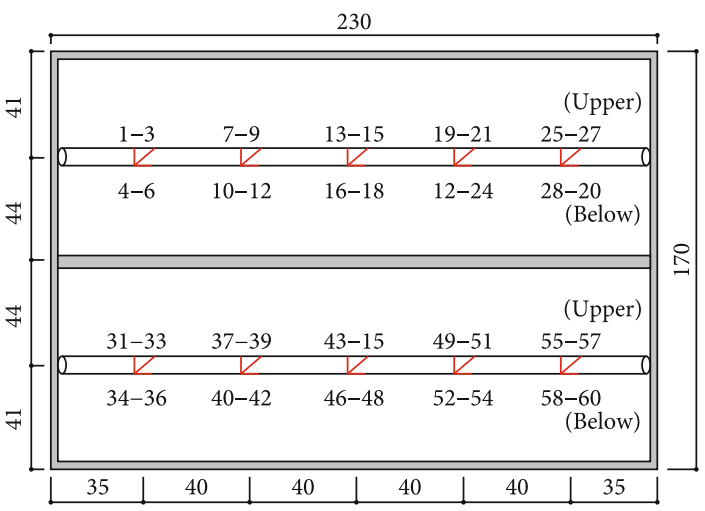

(e)

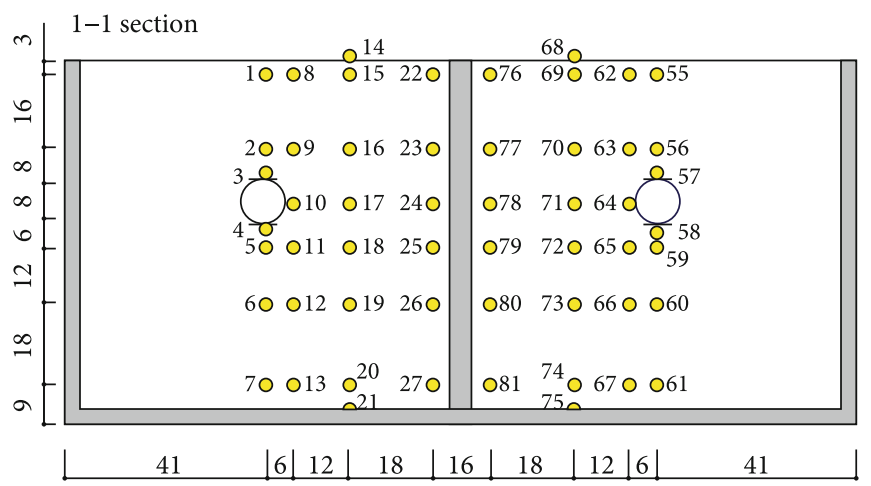

(d)

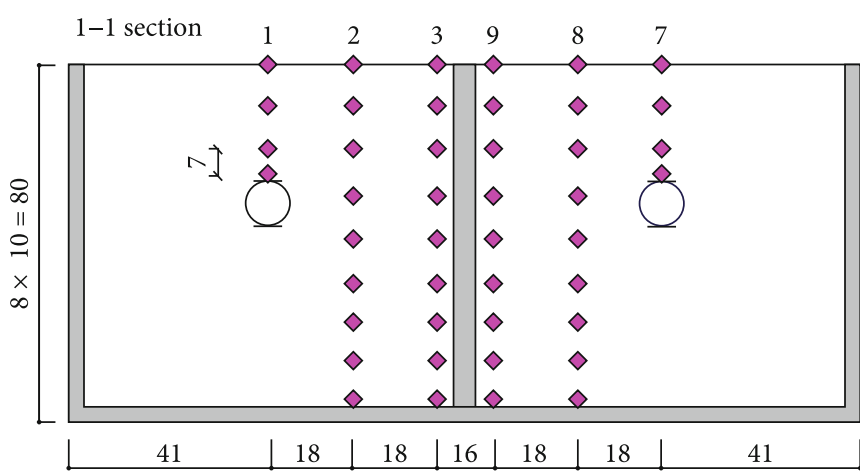

(f)

$\begin{array}{ll}\text { Displacement sensors } \quad<\text { Strain gauges } \\ \text { Temperature sensors } & \diamond \text { Water content }\end{array}$

FIGURE 6: Locations of measurement points (unit: $\mathrm{cm}$ ): (a) plan view, (b) section view, (c) displacement sensors, (d) temperature sensors, (e) stress gauges, and (f) water content test points. 
(3) Data acquisition systems: a series of sensors and data collection devices were installed in the model box to monitor the changes of pipeline and surrounding soil during the freeze-thaw cycle, including the temperature testing system, the displacement testing system, and the stress testing system. The above data collection devices were connected with a computer to observe and export the test data easily. Table 5 shows the specific parameters of the equipment

(4) Other equipment: a model box of $2.3 \mathrm{~m} \times 1.7 \mathrm{~m} \times$ $0.8 \mathrm{~m}$ (length $\times$ width $\times$ height) was installed in the freeze-thaw machine to fill the foundation and pipeline models. The lateral boundaries were assumed to be adiabatic and pasted with a rubber thermal insulation material with a thickness of $3 \mathrm{~cm}$, whose thermal conductivity was $0.034 \mathrm{w} / \mathrm{m} . \mathrm{k}$. In this experiment, we would like to verify the influence of the thermal insulation layer on the buried oil-gas pipelines in permafrost regions through a controlled trial, so the model box was separated into two parts of equal size, one side was the bare pipeline model, and the other side was the insulated pipeline (rubber thermal insulation layer with a thickness of $1 \mathrm{~cm}$ )

3.4. Experimental Procedures. The experiment system and equipment are shown in Figure 5, and the particular experiment procedures are described as follows:

(1) Soil sample preparation: in the pretest stage, the prepared humus soil sample was treated by a series of processes (organic matter removing, drying, sieving, weighing, and water content testing). Then, according to the initial water content of the soil sample obtained in situ, the water content of the humus soil was controlled at about $83 \%$ by adding water. Finally, the reshaped soil sample was sealed in a model box for 48 hours to ensure uniform water content before the model filling

(2) Model filling and equipment setup: as shown in Figure 6(b), the foundation model was divided into two layers filled successively, in which the degree of compaction of humus soil A was 0.7 and that of humus soil B was 0.8 . Frozen balloons with a diameter of about $10 \mathrm{~cm}$ were uniformly placed under the pipeline with a depth of $70 \mathrm{~cm}$, which was used to reflect the uneven distribution of frozen soil in sporadic permafrost regions. Then, the pipeline models were installed after the foundation soil was filled to the design height, and the waterproofing treatment was applied to the pipeline surface and ends. In addition, $32.5 \mathrm{~kg}$ quartz sand was evenly placed in the pipeline to increase the weight of the aluminium alloy pipeline, which was used to reflect the marked deformation law of the pipeline during freeze-thaw cycles

According to the symmetry principle of the pipeline models, all monitoring equipment was installed according

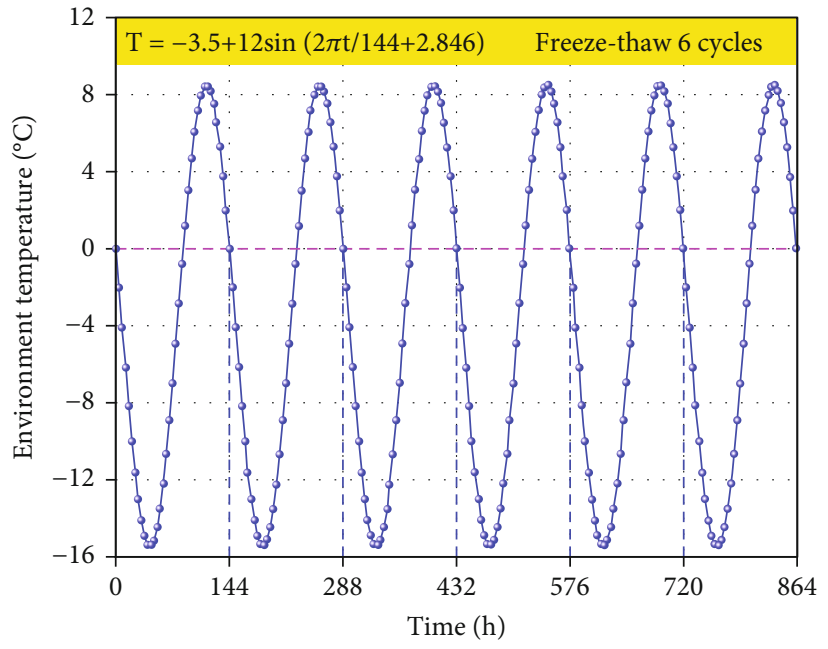

FIgURE 7: The ambient temperature boundary conditions of the model test.

to Figure 6 in the model filling process. Displacement sensors were installed at different depths $(d=0,15,35$, and $55 \mathrm{~cm}$ ) to monitor the deformation of the pipeline and foundation soil (Figure 6(c)). Temperature sensors were arranged at two monitoring sections ( $1-1$ section and $3-3$ section) to monitor the thawing range of the foundation soil during pipeline model operation (Figure 6(d)). Strain gauges were pasted on the upper and lower surface of the pipeline with an equal distance of $40 \mathrm{~cm}$ to monitor the stress changes in freeze-thaw cycles (Figure 6(e)).

(3) Temperature control: based on the adherent layer theory [44] and the in situ monitoring data of ambient temperature in the Laji mountain area, the thermal boundary conditions of the model test could be expressed as follows:

$$
T=-3.5+12 \sin \left(\frac{2 \pi t}{144}+2.846\right)
$$

We designed six cycles in this experiment, and the sinusoidal ambient temperature control curve is shown in Figure 7. Before the freeze-thaw cycle, the foundation soil around the buried pipelines was frozen at $-12^{\circ} \mathrm{C}$ for 52 days, and the soil temperature distribution of the two groups parallel tests have tended to be stable. At this time, the initial soil temperature at the bottom of the model box reached $-0.8^{\circ} \mathrm{C} \sim-1^{\circ} \mathrm{C}$. Then, the temperature inside the pipeline was set to $+6^{\circ} \mathrm{C}$ and kept constant by the intelligent temperature controller.

(4) After the end of the sixth freeze-thaw cycle, the soil samples were taken out quickly by using a special sampling tool according to the measurement points in Figure 6(f) and the water content was measured by the drying method 


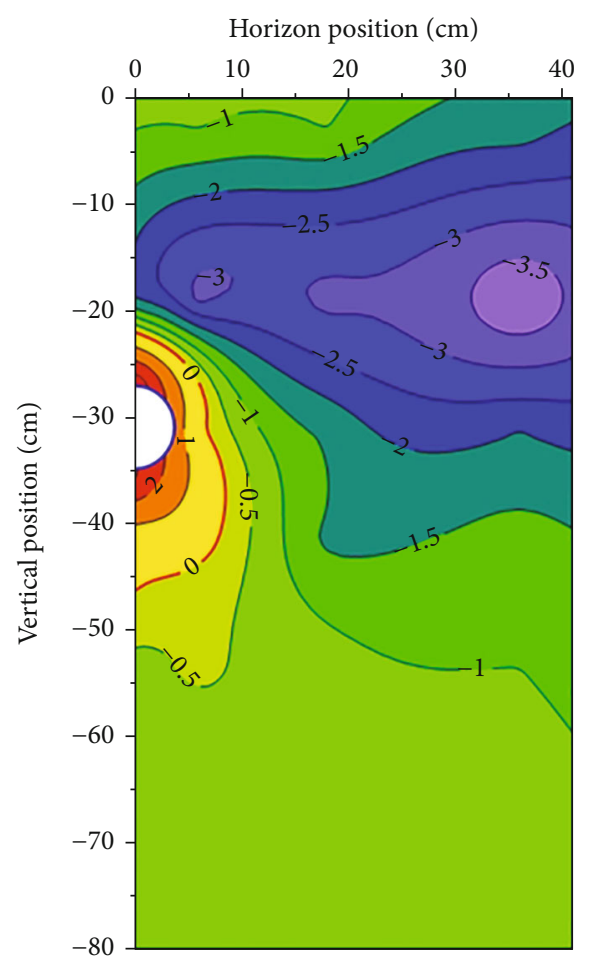

(a) 1 cycle

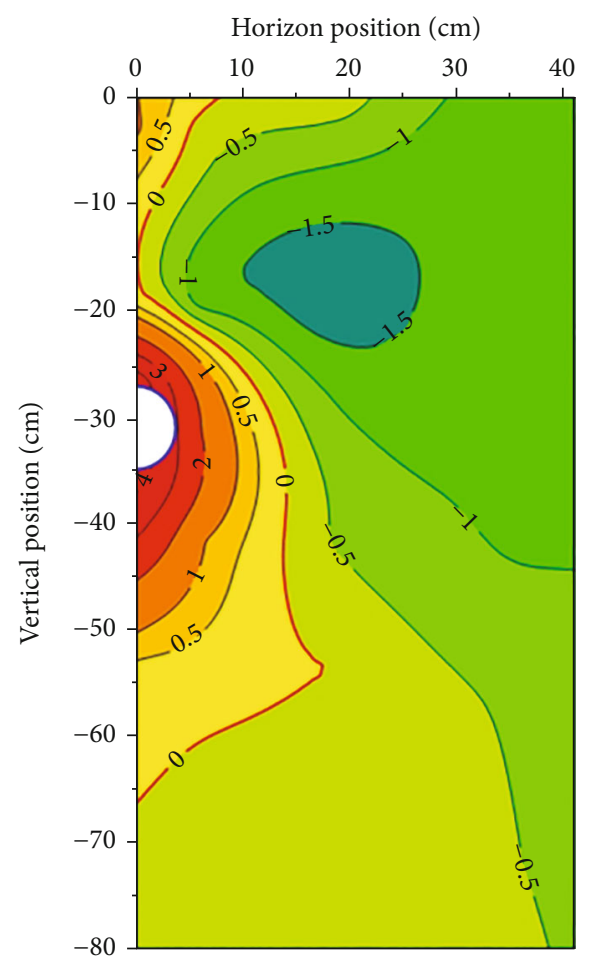

(c) 3 cycles

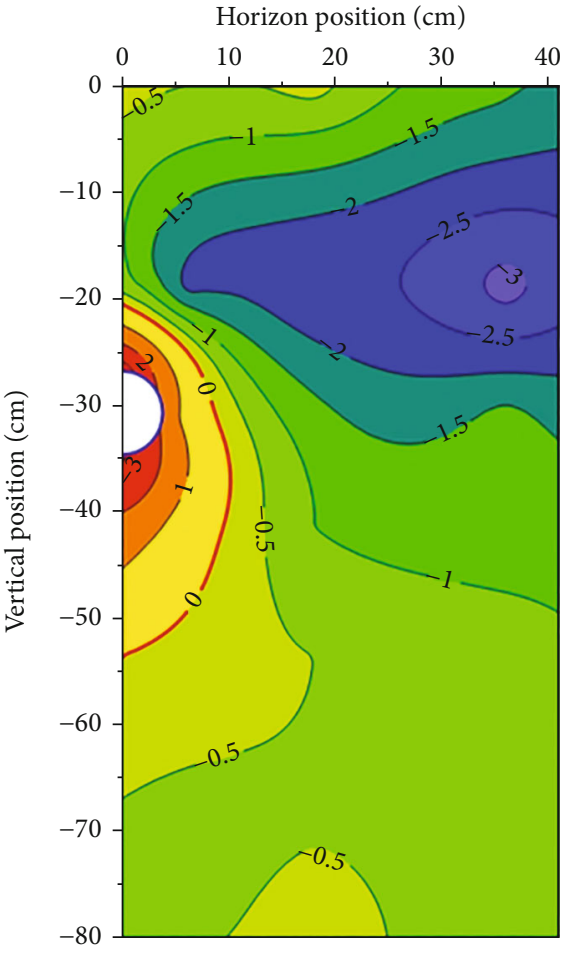

(b) 2 cycles

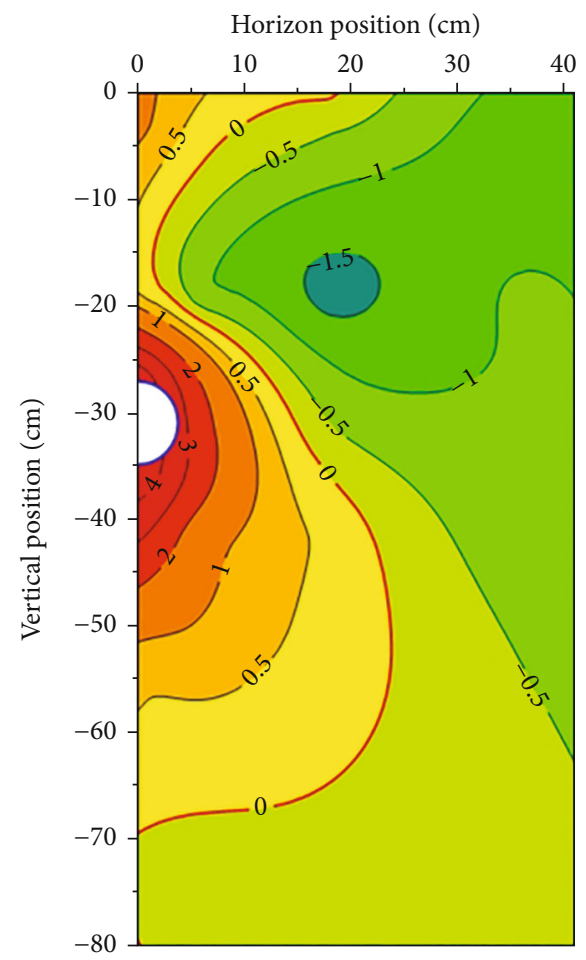

(d) 4 cycles

Figure 8: Continued. 


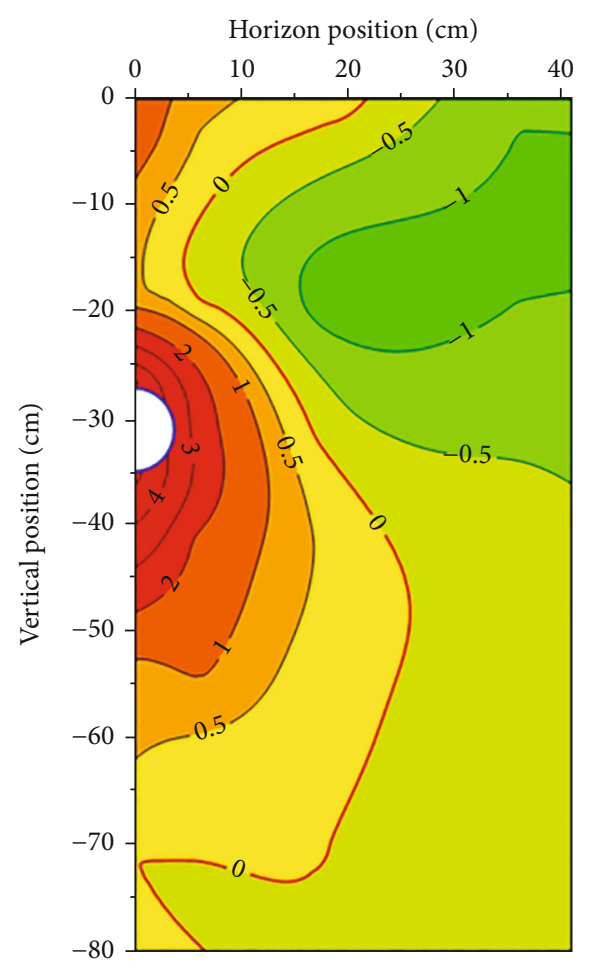

(e) 5 cycles

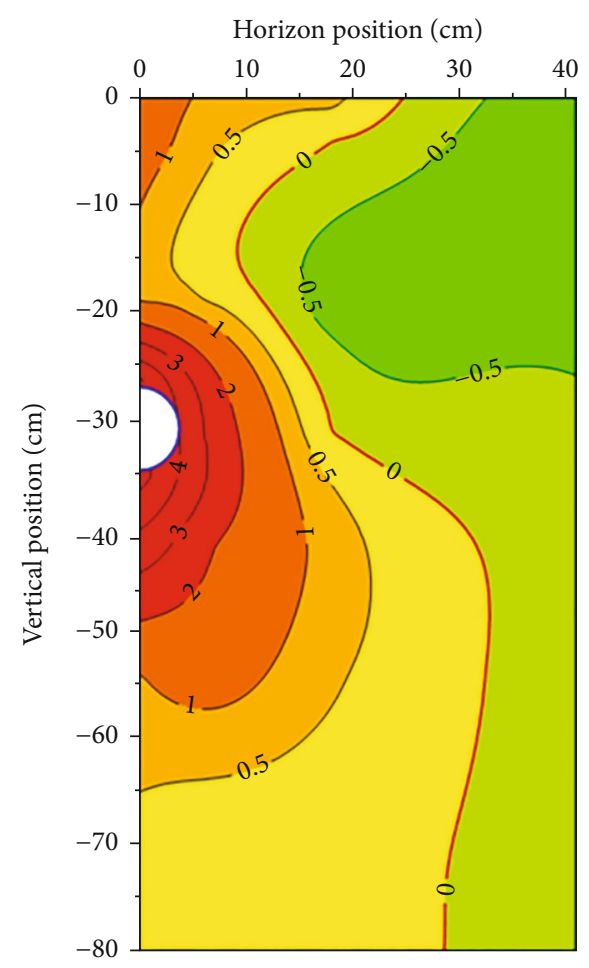

(f) 6 cycles

Figure 8: Temperature regime around the bare pipeline model at different freeze-thaw cycles: (a) $t=144 \mathrm{~h}$, (b) $t=288 \mathrm{~h},(\mathrm{c}) t=432 \mathrm{~h},(\mathrm{~d})$ $t=576 \mathrm{~h}$, (e) $t=720 \mathrm{~h}$, and (f) $t=864 \mathrm{~h}$.

\section{Results and Discussion}

4.1. Temperature Regime around the Pipelines. In order to avoid the influence of the model box on the temperature regime around the pipelines, we selected the temperature sensor data of $1-1$ cross section in the middle of the bare/insulated pipeline for analysis. The distributions of the temperature regime at the end of each freeze-thaw cycle $(t=144,288,432,576,720$, and $864 \mathrm{~h})$ are presented in Figures 8 and 9 . Figure 8 shows that the isotherms around the bare pipeline are smooth in the thaw stage because of sufficient heat transfer inside the foundation soil. The foundation soil of the surface layer within $20 \mathrm{~cm}$ is greatly influenced by the environmental temperature in the model box; it thaws in the positive temperature stage and freezes in the negative temperature stage. However, due to the continuous heat release of the bare pipeline model, the temperature of the surface soil above the pipeline is higher than $0^{\circ} \mathrm{C}$ at the end of the third cycle, which leads to the formation of a thaw channel above the bare pipeline, which gradually increases with the freezethaw cycles. In addition, there is no extra cold supply at the bottom and around of the model box in this experiment, so we can see that foundation soil under the bare pipeline obviously thaws during freeze-thaw cycles and the exothermic process of the pipeline (Figure 8). The $-2^{\circ} \mathrm{C}$ isotherms disappear at the end of the third cycle, and the $-1{ }^{\circ} \mathrm{C}$ isotherms degenerate at the end of the sixth cycle. Finally, the foundation soil under the bare pipeline was thawed by $75 \%$ after the test, which results in a differential thaw settlement and consolida- tion of the foundation soil. Permafrost degradation reduces the bearing capacity of the pipeline foundation, and it is extremely easy to cause plenty of pipeline faults in practical engineering, such as pipeline trench subsidence and pipeline trench thaw slumping, which seriously affects the safe operation of the buried oil-gas pipelines in permafrost regions [3, $8,17,27]$.

To prevent uplift/downward buckling of the buried oilgas pipelines from differential frost heave and thaw settlement in permafrost regions, many mitigative engineering measurements including a thermal insulation layer, twophase closed thermosyphon, and U-shaped air-ventilated pipes are applied to minimise permafrost degradation and ensure the thermal stability of permafrost foundations [21, $22,24]$. The thermal insulation layer is more convenient than other mitigation measures, but its effectiveness needs to be further verified. Figure 9 shows the temperature regime around the insulated pipeline at different freeze-thaw cycles, and the isothermals around the insulated pipeline are denser due to the circumferential heat release. The thermal resistance of the rubber thermal insulation layer plays a great role in protecting against permafrost, which ensures that the $0^{\circ} \mathrm{C}$ isotherms do not appear until the end of the second cycle. The thaw bulb around the insulated pipeline increases gradually with heat exchange between the pipelines and the foundation soil. However, the thawing rate decreases gradually and tends to a balanced state, which can also be clearly observed in later sections of pipeline wall stress and vertical displacement. Moreover, there is no thaw channel above the 


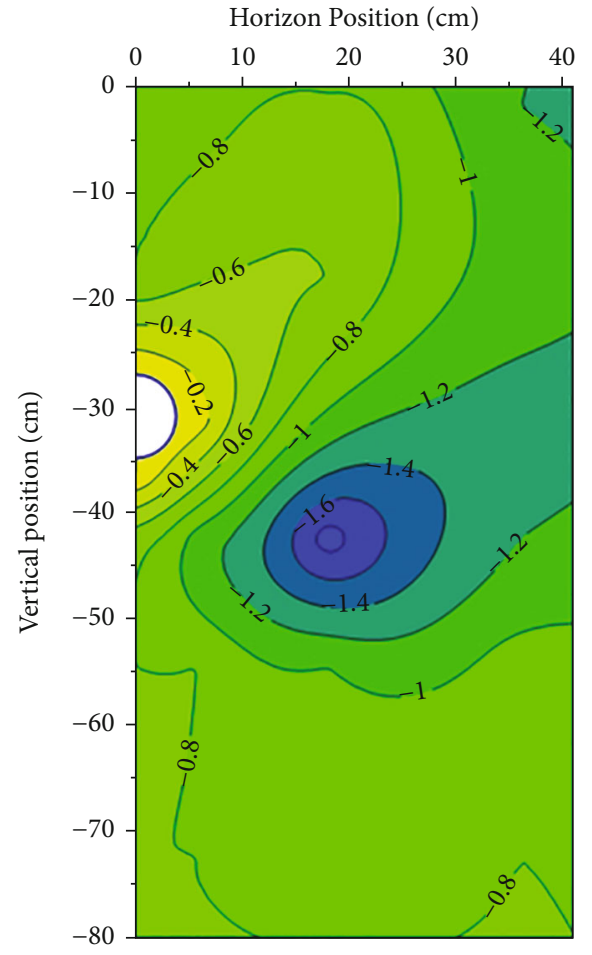

(a) 1 cycle

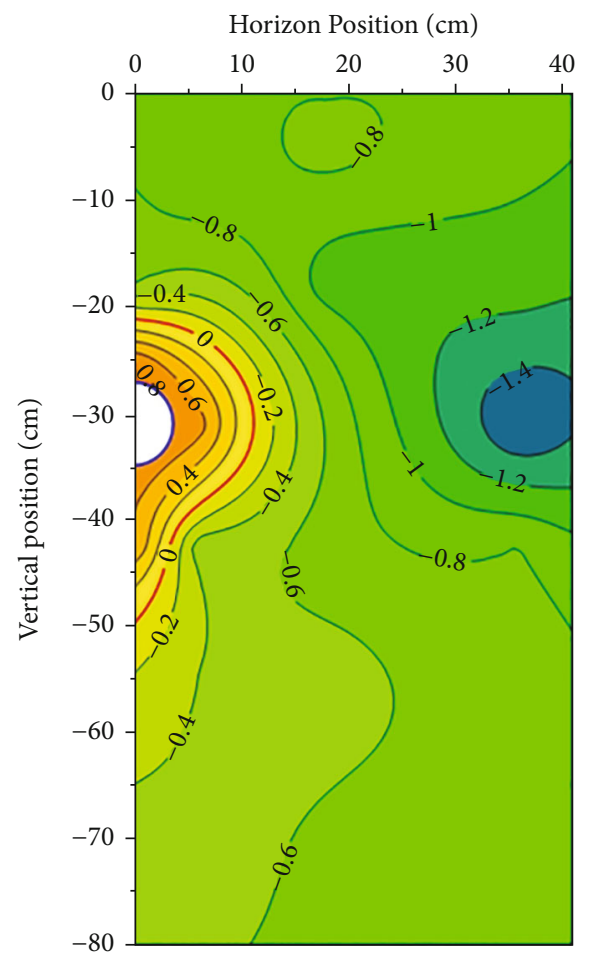

(c) 3 cycles

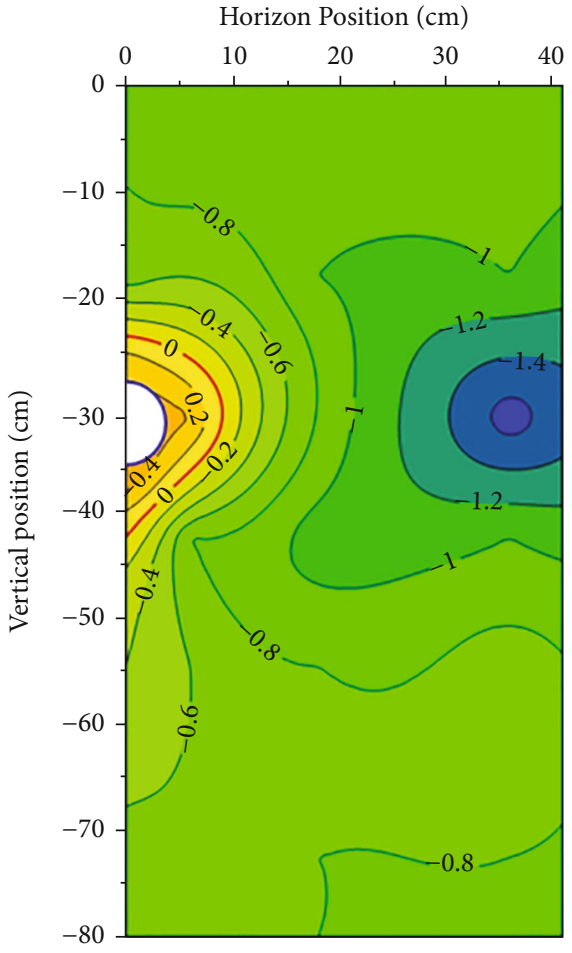

(b) 2 cycles

Horizon Position $(\mathrm{cm})$

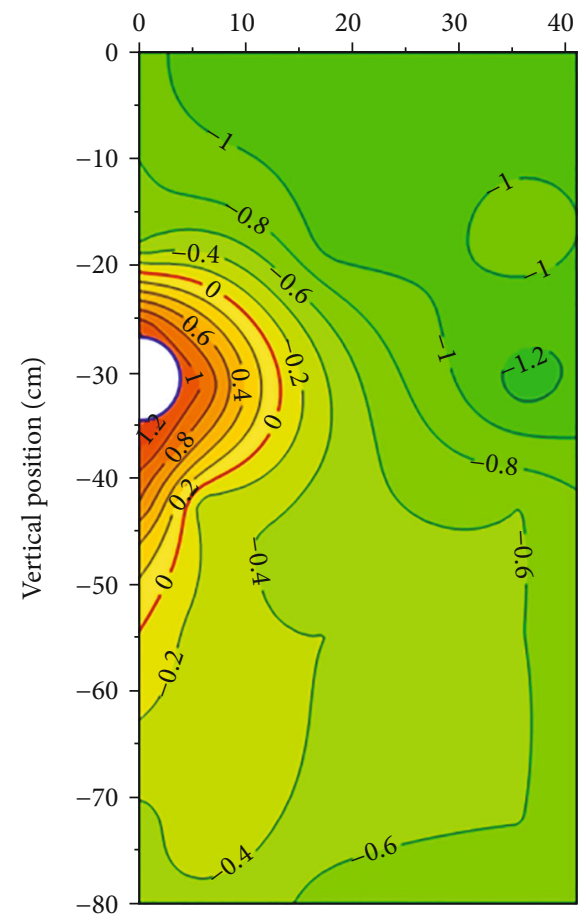

(d) 4 cycles

FIgURe 9: Continued. 


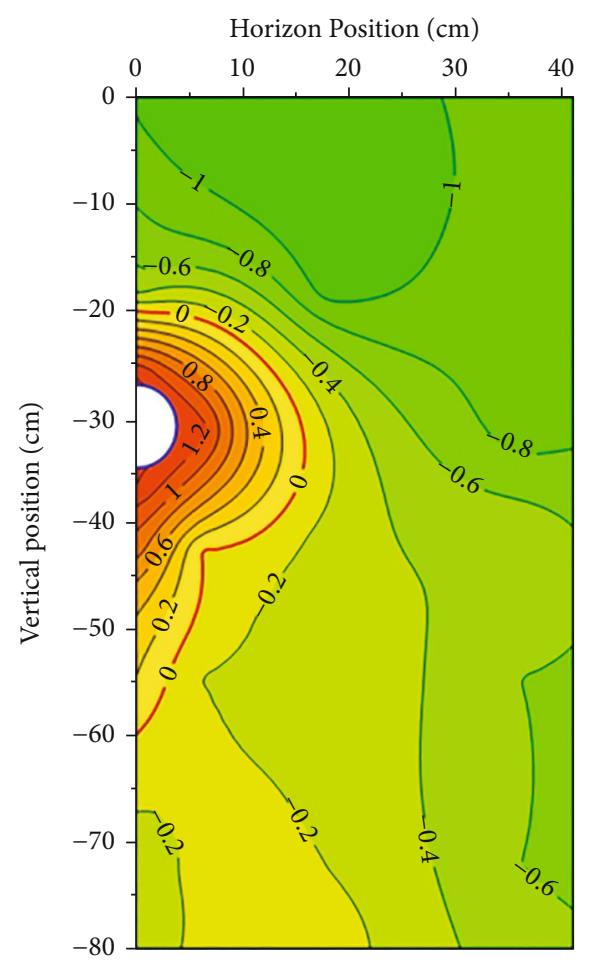

(e) 5 cycles

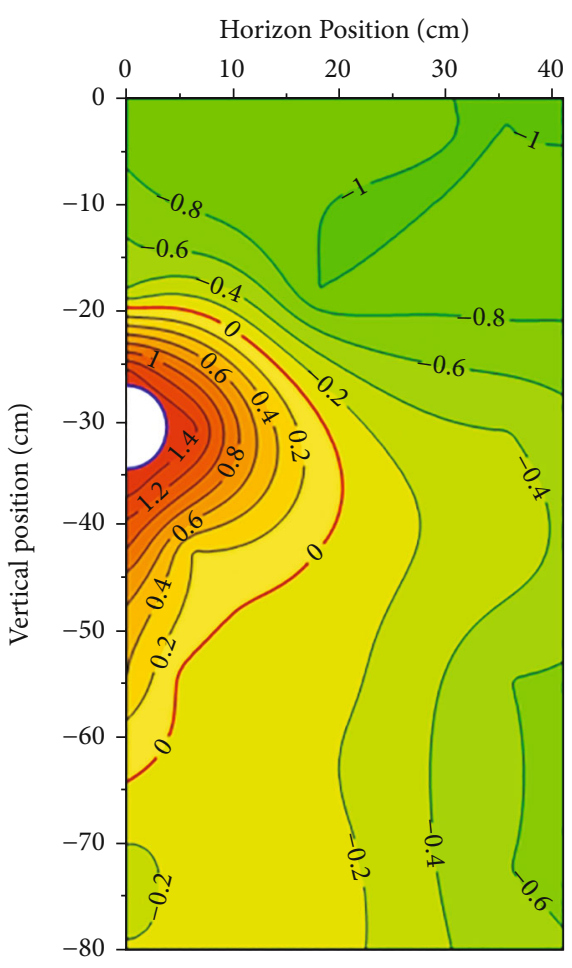

(f) 6 cycles

FIGURE 9: Temperature regime around the insulated pipeline model at different freeze-thaw cycles: (a) $t=144 \mathrm{~h}$, (b) $t=288 \mathrm{~h},(\mathrm{c}) t=432 \mathrm{~h}$, (d) $t=576 \mathrm{~h}$, (e) $t=720 \mathrm{~h}$, and (f) $t=864 \mathrm{~h}$.

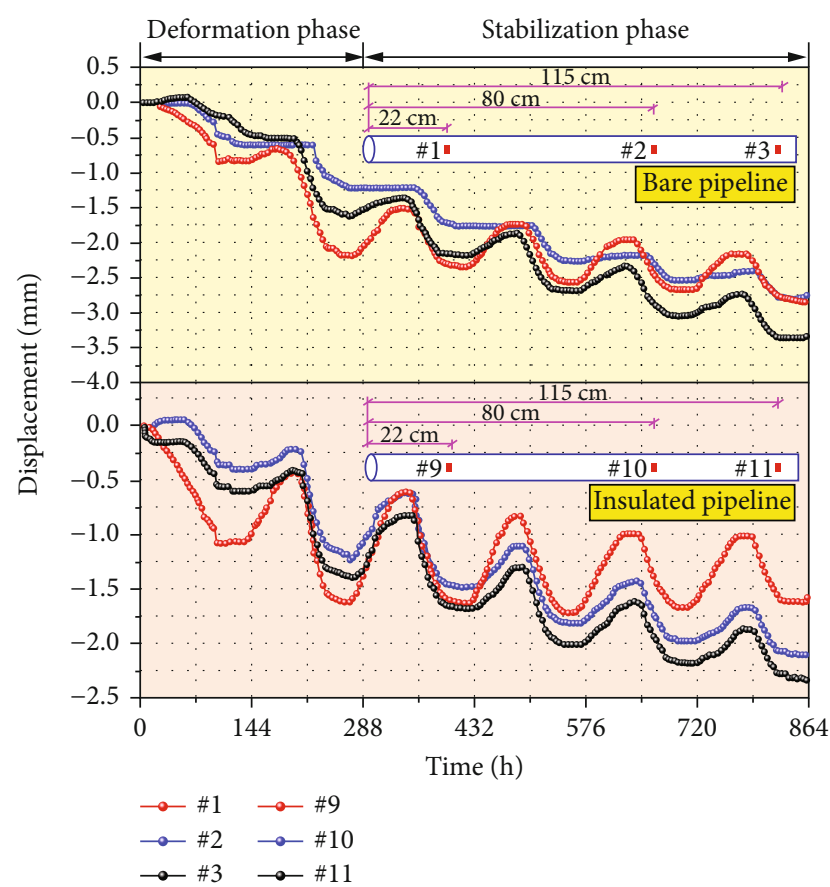

FIGURE 10: Vertical displacement variation of buried pipelines with freeze-thaw cycles at different positions.

insulated pipeline, and most of the foundation soil is in a frozen state at all times. After the end of the sixth freezethaw cycle, the horizontal thawing range of the foundation soil around the insulated pipeline is less than half that of

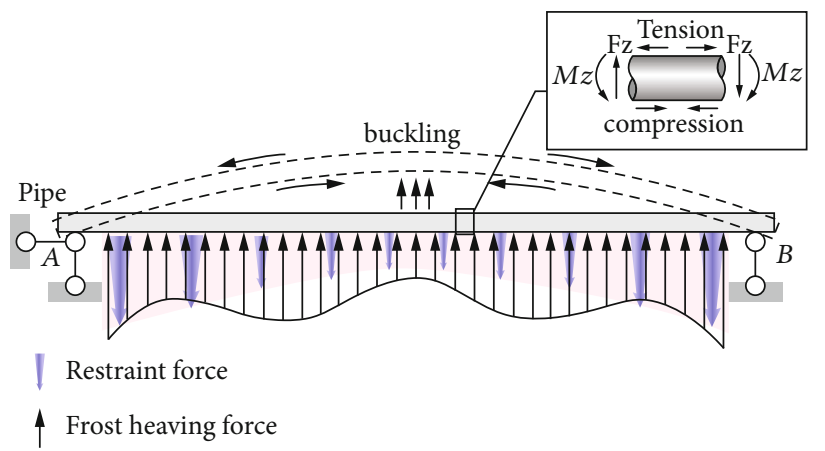

FIGURE 11: Simplified schematic of pipeline model similar to buckling arch [37].

the bare pipeline, and the vertical thawing depth is only 35 $\mathrm{cm}$ (Figure 9). The results indicate that the application of thermal insulation layer to prevent permafrost degradation around the oil-gas pipelines is effective. In addition, the ageing rate of thermal insulation materials will accelerate with the increase of service years in practical engineering, and the thermal insulation performance will gradually weaken under the freeze-thaw cycles [45]. Consequently, further studies on the new insulation materials and the optimal laying thickness are still necessary, and they will be summarised in our next study.

4.2. Vertical Displacement of Pipeline and Surrounding Soil. Frost heave and thaw settlement occur in foundation soil with periodic fluctuations of air temperature, which makes 


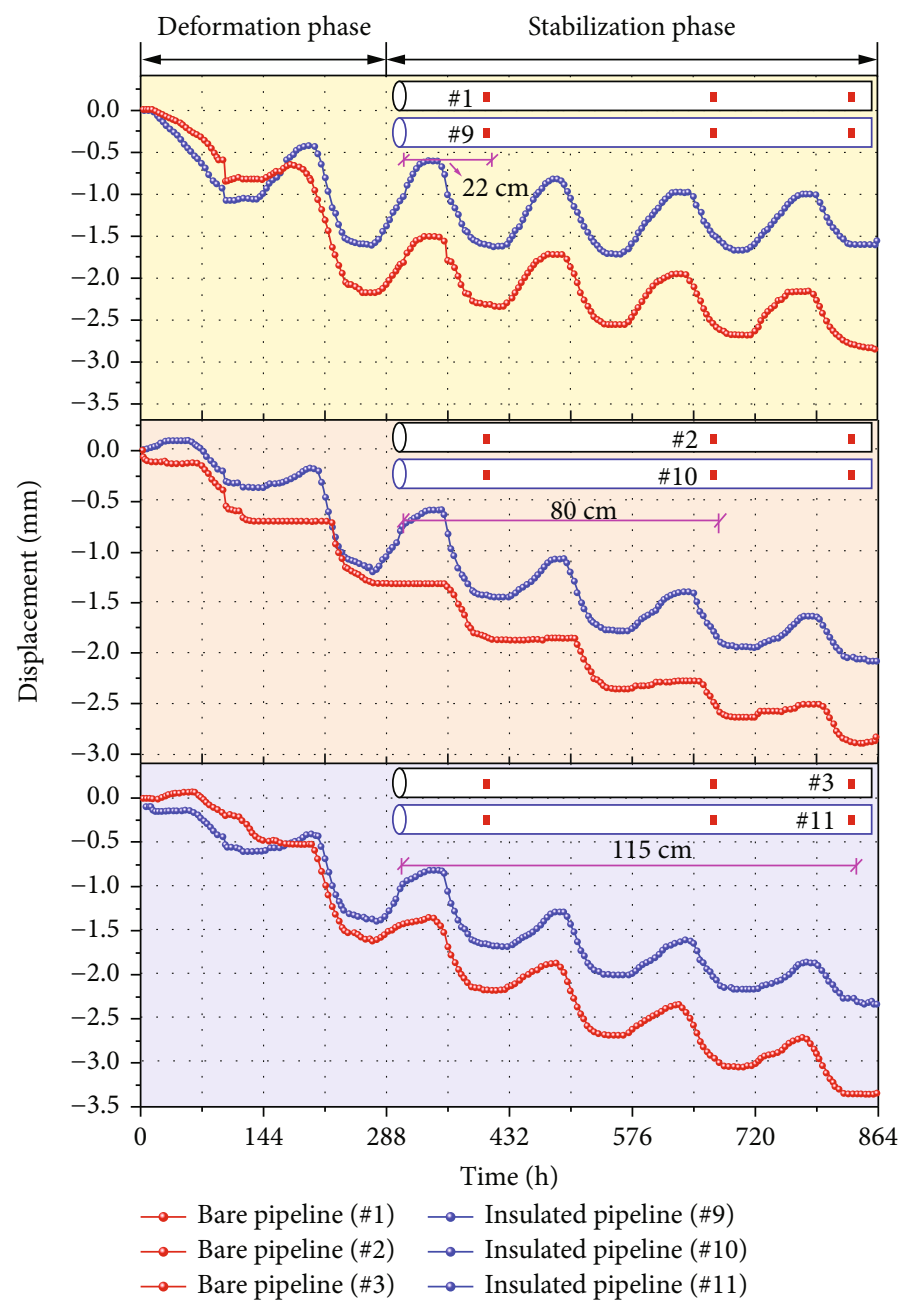

FIGURE 12: Comparison of vertical displacement variation between the bare pipeline and the insulated pipeline at different positions.

the buried pipelines move up and down regularly. During the freezing period, a portion of pore water migrates through the unfrozen zone towards a freeze surface by temperature gradient, in which the pore water is partially solidified into ice lenses during this process. Frost heave will occur due to the phase change of ice-water which increases in volume by about $9 \%$, causing uplift deformation of the buried pipelines. When the environmental temperature rises, the buried oil-gas pipelines will move down gradually with permafrost foundation thaw settlement [1].

Figure 10 shows the vertical displacement variation of the buried pipelines with freeze-thaw cycles at different positions (negative sign represents subsidence of pipelines and surrounding soil). First, the bare pipeline and insulated pipeline still move down in the first freeze-thaw cycle, which does not mean that there is no frost heave in the foundation soil during freezing time. In contrast, the sudden heat release of the buried pipelines will produce a marked and continuous disturbance to the surrounding foundation, which is much larger than frost heave, but the especially obvious uplift deformation of the bare pipeline does not appear until the third cycle. Second, according to the deformation rate of the buried pipelines, vertical displacement variation of the pipeline can be divided into two stages. Before the third freeze-thaw cycle, the pipeline and surrounding soil are in a large deformation phase, and for the remaining time they are in a stabilisation phase. The frost heave and thaw settlement are obvious in the stabilisation phase, which corresponds to a regular up and down movement of the buried pipeline. Furthermore, the overall trend of vertical displacement is increasing due to continuous expansion of the thaw bulb around the pipelines, but the subsidence rate of the pipeline and surrounding soil decreases gradually. Third, the phase change of the pore water needs time, and it occurs in the temperature range $\left(T_{\mathrm{m}} \pm \Delta T\right)[40,41,46]$. Therefore, the vertical displacement change lags by $1 / 4$ cycle in time compared with the temperature. Finally, it can be assumed that the buried pipelines are similar to a buckling arch constrained by pipeline bearings (Figure 11) [37]. In theory, the maximum bending moment and deformation occur in the middle cross section of buckling arch during frost heave and thaw settlement, which has also been verified in this experiment as shown in Figure 10.

As mentioned in the temperature regime part, the thermal insulation layer can mitigate permafrost degradation to some extent. Figure 12 shows the comparison of vertical 


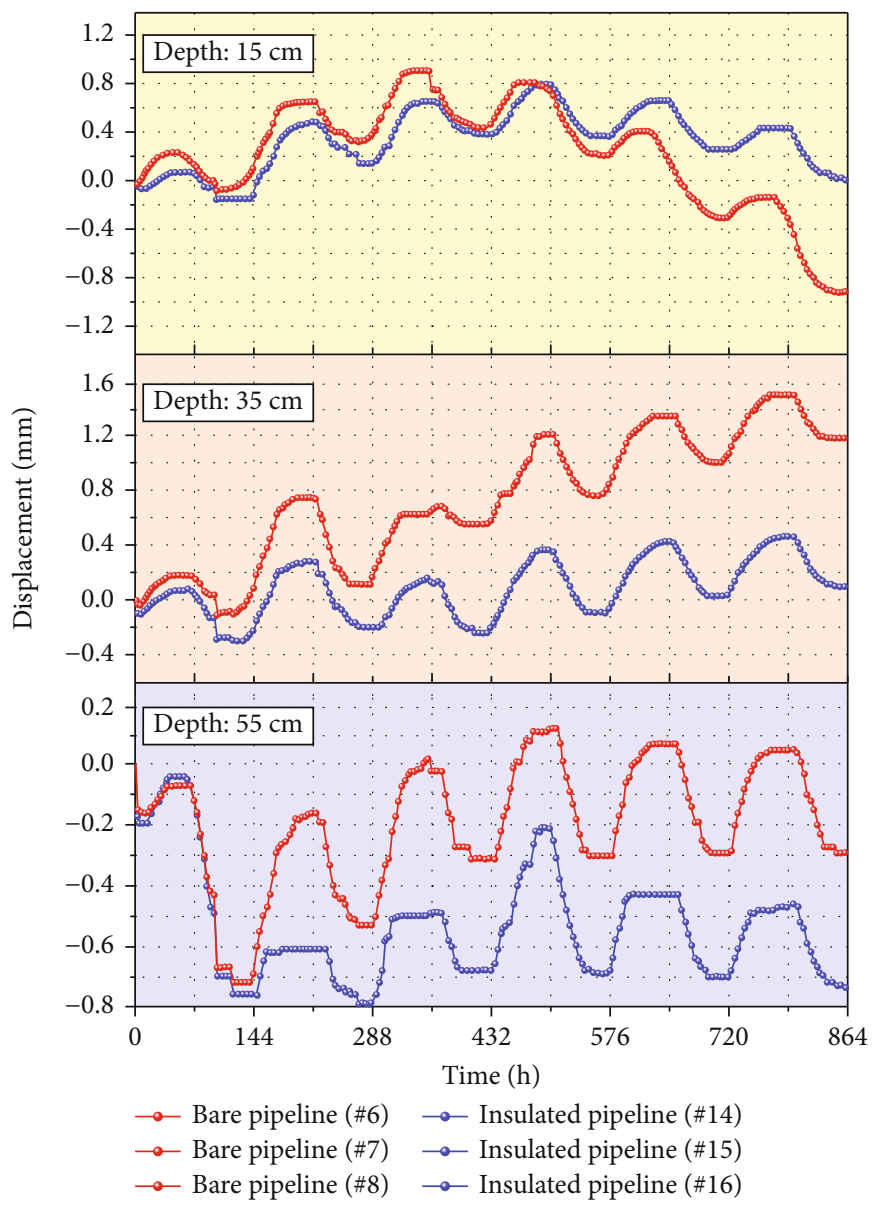

FIGURE 13: Vertical displacement variation of permafrost foundation at different depths.

displacement variation between the bare pipeline and the insulated pipeline at different positions. Evidently, the vertical displacement of the insulated pipeline is less than that of the bare pipeline. After the end of the sixth freeze-thaw cycle, the vertical displacement of the insulated pipeline measured at the middle cross section is $-2.44 \mathrm{~mm}$, which decreases by $26.9 \%$ compared with the bare pipeline, -3.34 $\mathrm{mm}$. In addition, Figure 12 also shows that the deformation rate of the insulated pipeline is less than that of the bare pipeline, which indicates that the thermal insulation materials play an active role in ensuring safe and stable operation of the oil-gas buried pipelines in the service years.

In this experiment, we also directly measured the vertical displacement variation of foundation soil at different depths. Figure 13 shows that the displacement of the permafrost foundation fluctuates periodically with freeze-thaw cycles. Moreover, the deformation range of the foundation soil gradually decreases with depth, and the regularity of frost heave and thaw settlement is most obvious at the depth of $55 \mathrm{~cm}$ due to less impact of air temperature, which is similar to the in situ situation [17]. In addition, permafrost deformation above the buried pipelines is larger than that of the surrounding foundation. In other words, the further away the humus soil is from the pipeline, the smaller the deformation and vice versa (Figure 12). Finally, uplift deformation caused by frost heave increases gradually at the depth of 35 $\mathrm{cm}$ and reaches $1.48 \mathrm{~mm}$ in the sixth freeze-thaw cycle. When the air temperature rises, the pore water will accumulate near the thaw bulb with the thawing of ice lenses here. At the same time, the remaining pore water will also migrate to the freezing surface and redistribute again in freezing time, which leads to more obvious frost heave deformation in the next cycle.

4.3. Pipeline Wall Stress. We assume that the buried pipelines are in close contact with the surrounding soil, and the wall stress of the pipeline will change following the freeze heave and thaw settlement of the foundation soil. In this part, the stress variation on the lower surface of the pipelines at three typical cross sections $(l=35,75$, and $115 \mathrm{~cm})$ will be analysed. First, Figure 14 shows that compression occurs in the whole freeze-thaw cycles (positive sign represents compression and vice versa). The uplift deformation of the pipeline caused by frost heave occurs at the initial freezing time, which cannot be restored completely in the spring-thawing seasons, and residual deformation may exist and accumulate gradually [1]; the maximum frost heave force reaches 22.89 $\mathrm{MPa}$ at the middle cross section of the bare pipeline. Therefore, the stress accumulation of the pipeline cannot be ignored in permafrost regions, which seriously threatens the safe operation of the buried oil-gas pipelines. According to the in situ investigation [8], the Golmud-Lhasa oil 


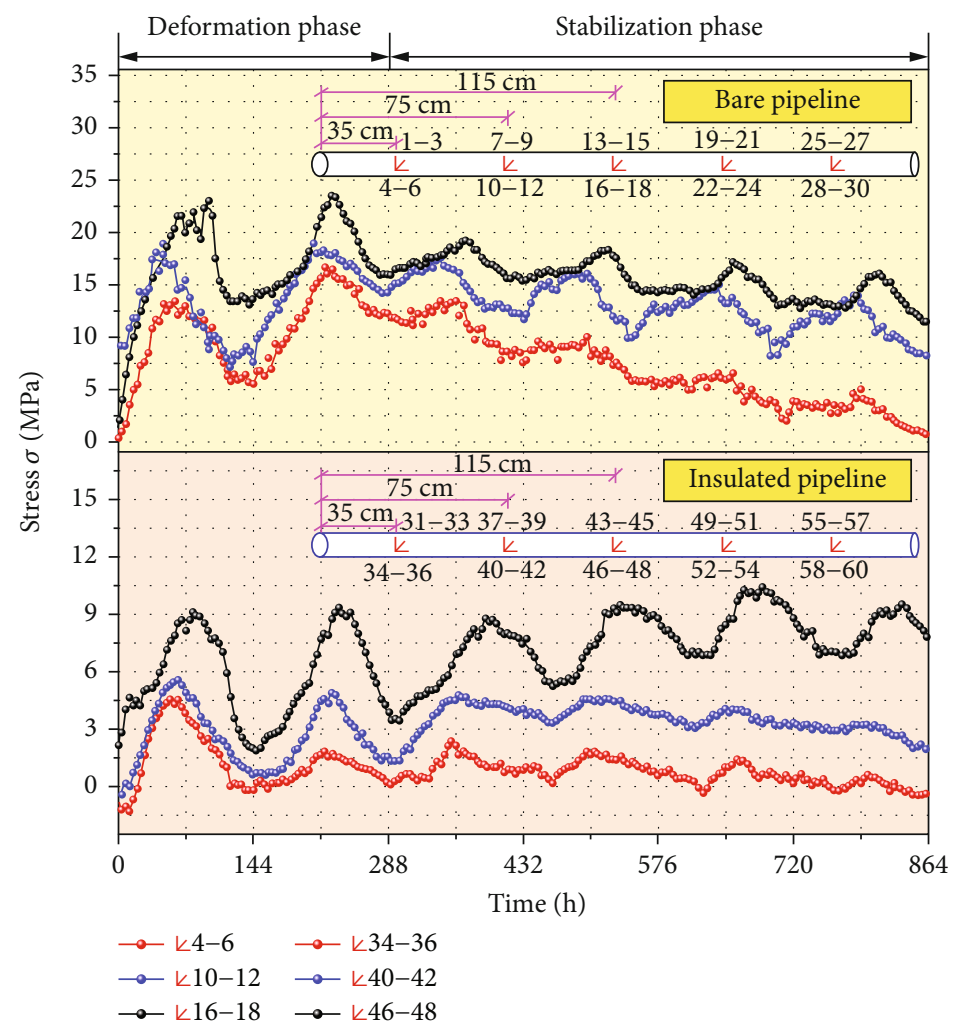

FIGURE 14: Stress variation of the buried pipelines with freeze-thaw cycles at different positions.

product pipeline was uplifted onto the surface at Wuli in June 2002, forming a buckling arch with a maximum height of about $0.7 \mathrm{~m}$ (Figure $2(\mathrm{~d})$ ). When the air temperature rises, compression on the pipeline lower wall decreases gradually due to thaw settlement of the foundation soil. Second, Figure 14 also shows that the maximum stress appears in the middle cross section of the pipelines, as mentioned in the vertical displacement section, which is caused by the special constraint of pipeline bearings [37]. Third, the stress variation of the buried pipelines tends to be stable after the second cycle. At the same time, the phenomenon of stress hysteresis is obvious in the stabilisation phase due to differential freeze heave and thaw settlement. Consequently, we should also pay more attention to the stress accumulation of the buried oil-gas pipelines at the initial thawing time.

Thermal insulation layer, as an effective insulation measure, can reduce wall stress accumulation of the buried oilgas pipelines in freeze-thaw cycles. Figure 15 shows that the stress on lower wall of the insulated pipeline is far less than that of the bare pipeline, and the two main reasons are as follows. On the one hand, thermal insulation material has good thermostability, and this characteristic makes the heat release rate of positive temperature oil-gas pipelines decrease significantly in freeze-thaw cycles. Therefore, the thawing range of the permafrost foundation around the insulated pipeline is only half that of the bare pipeline (Figure 9). At the same time, the frost heave deformation of the insulated pipeline is also smaller than that of the bare pipeline in freezing time (Figure 12). Compared with the bare pipeline, the maximum frost heave force of the insu- lated pipeline in the first freeze-thaw cycle reduces by 66.2 $\%, 68.8 \%$, and $60.4 \%$ at locations of 35,75 , and $115 \mathrm{~cm}$, respectively. On the other hand, thermal insulation material, as a separation layer, has a certain thickness. It can be considered that the elastic properties of the rubber insulation cotton will also eliminate a small part of the frost heave force in this test. Overall, the thermostability of the thermal insulation layer occupies a dominant position in the above two main reasons. Furthermore, the experimental research results will hopefully serve as useful feedback information for allowable stress design for the buried oil-gas pipelines in permafrost regions.

4.4. Distributions of Water Content around the Pipelines. Figure 16 shows that redistribution of the pore water is obvious at $1-1$ cross section after the sixth freeze-thaw cycle. The initial water content of the foundation soil is approximately $83 \%$, but the water content of the upper foundation soil is much larger than that of the lower soil and exceeds $100 \%$ after the test. As mentioned in the temperature regime part, the thaw bulb around and below the pipelines increases gradually with heat release of the pipelines, but the temperature of upper soil affected by low temperature decreases during the freezing time, so a freezing surface is generated. Therefore, the pore water will be induced to migrate from the unfrozen zone to the freezing zone by a temperature gradient.

In addition, thermal insulation materials such as EPS and XPS have low water absorption, which can also effectively prevent water migration under the insulated pipeline by weakening the driving force. Therefore, the water content 


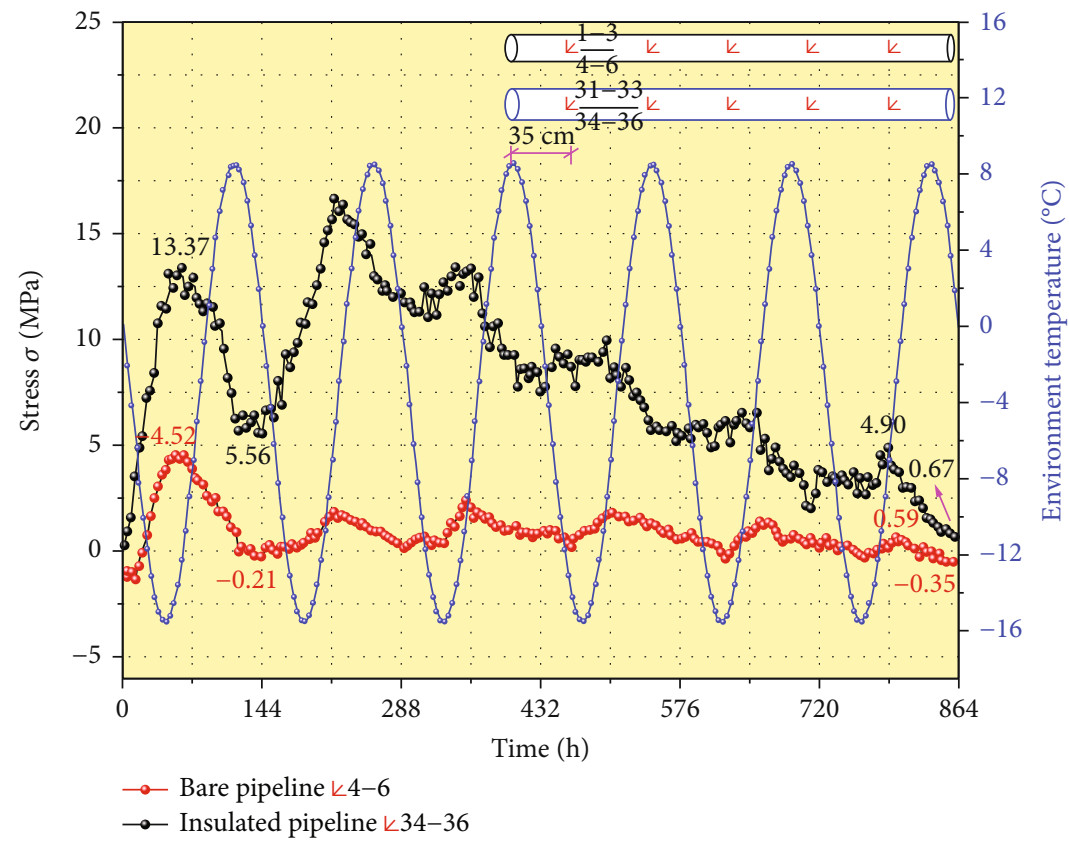

(a) $l=35 \mathrm{~cm}$

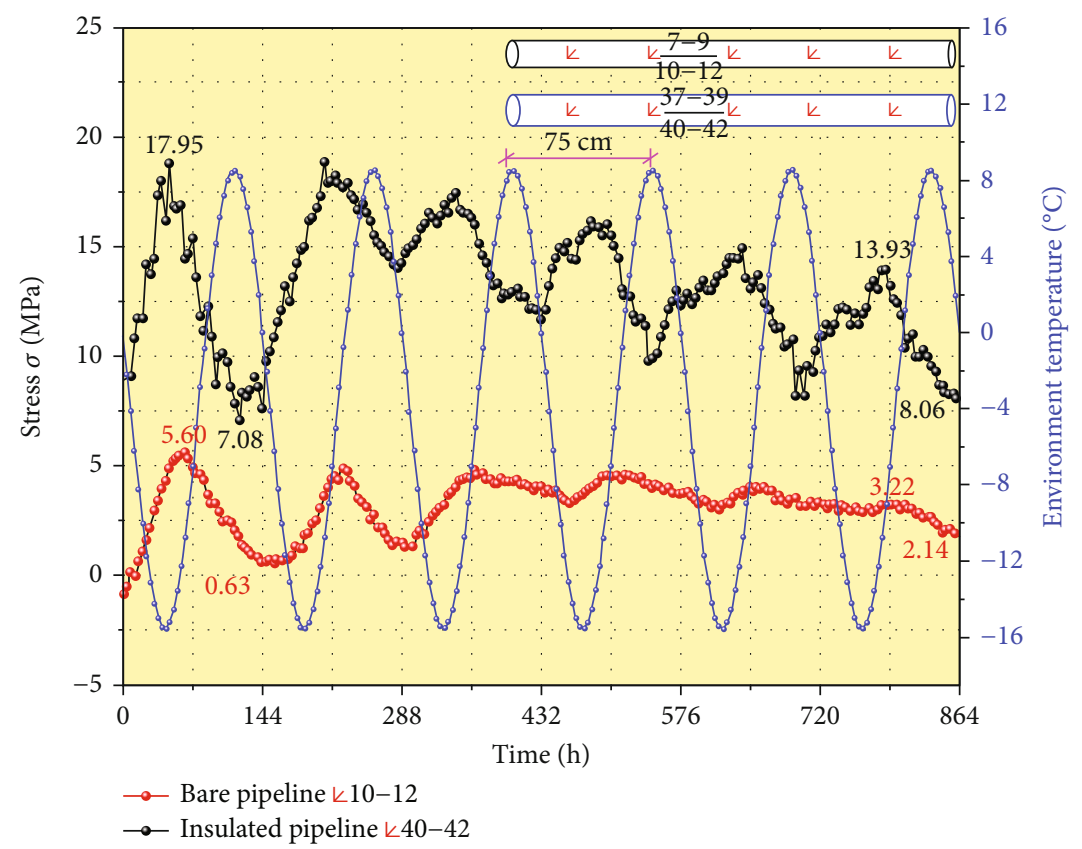

(b) $l=75 \mathrm{~cm}$

FIgURE 15: Continued. 


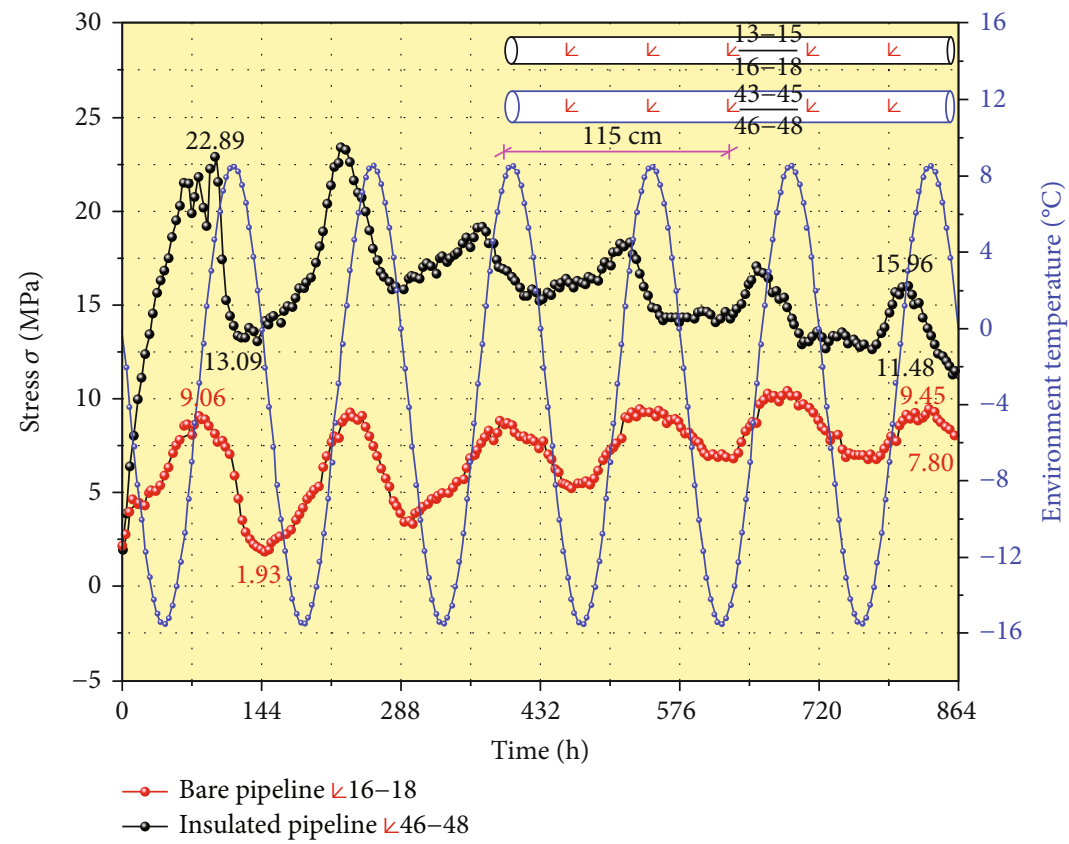

(c) $l=115 \mathrm{~cm}$

Figure 15: Comparison of stress variation between the bare pipeline and the insulated pipeline at different positions.
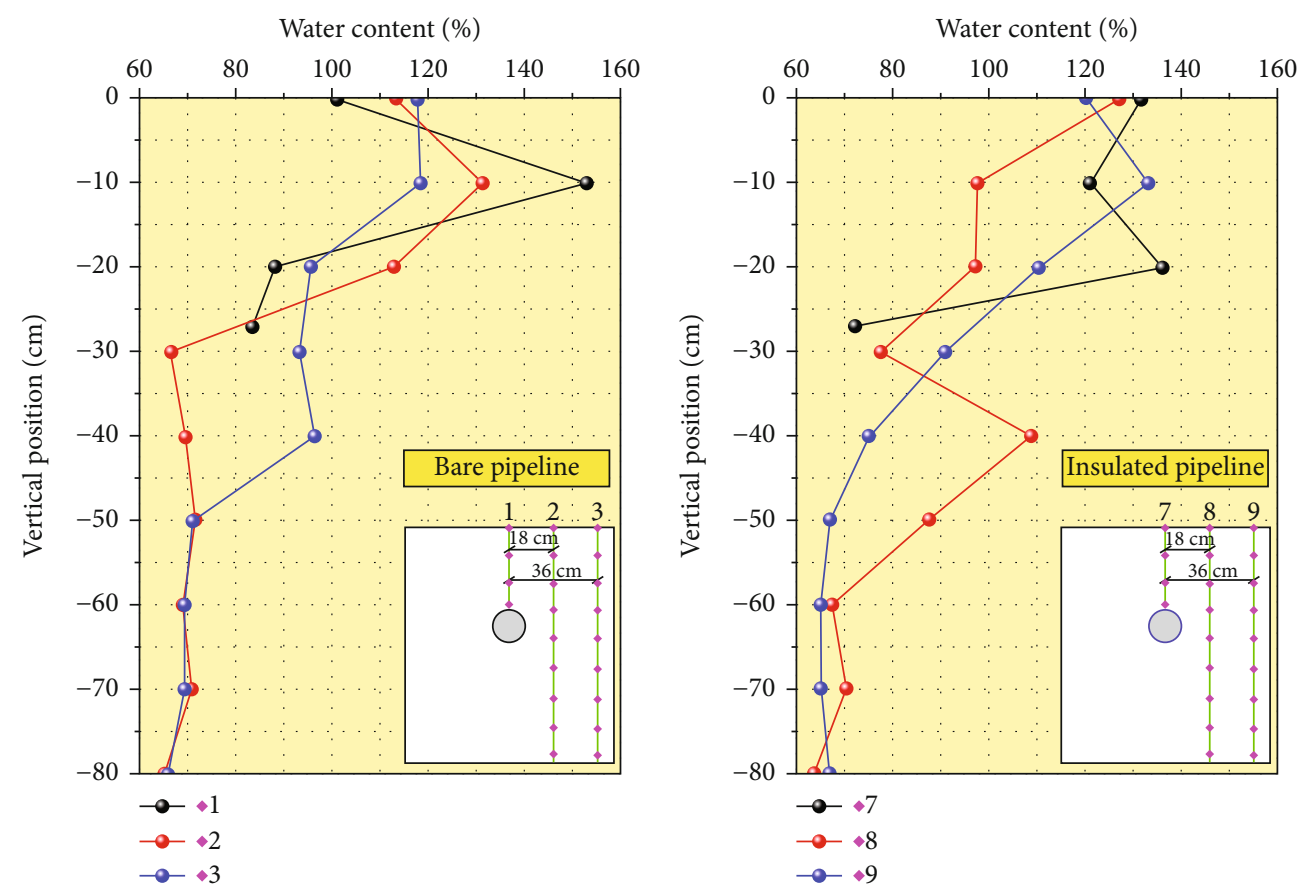

Figure 16: Distributions of water content around the pipelines after the sixth freeze-thaw cycle.

at the upper soil of the bare pipeline is larger than that of the insulated pipeline. Figure 16 shows that the water content of \#1 reaches $152.9 \%$ at the depth of $10 \mathrm{~cm}$. Furthermore, a large amount of water accumulation will lead to significant frost heave deformation in the surface soil, which is extremely unfavourable to the safe and stable operation of the pipeline. Meanwhile, the water content of humus soil around the pipelines is high in practical engineering
[16-18]. Hence, an extensive study of the frost heave deformation caused by water migration during freezing time is of great importance and cannot be ignored.

\section{Conclusion}

In permafrost regions, long distance buried pipelines, as a reliable and economical transportation way, have been 
widely used to transport oil and natural gas resources. However, pipeline faults occur frequently during freeze-thaw cycles and heat release of the pipeline. Therefore, in this paper, the method of thermal insulation layer was applied to mitigate permafrost degeneration. At the same time, an indoor model test was carried out, in which mechanical interaction between the buried pipelines and the foundation soil was studied systematically. Based on the results and discussion, the following conclusions can be drawn:

(1) The continuous heat release of the buried pipelines breaks the original thermal balance in permafrost regions. When the air temperature rises, thaw settlement of frozen soil around the bare pipeline is obvious, even forming a thaw channel above the bare pipeline. In contrast, a thermal insulation layer effectively slows down the thawing rate of the permafrost foundation. After the test, the horizontal thawing range of the foundation soil around the insulated pipeline is half that of the bare pipeline

(2) The vertical displacement of foundation soil at different depths fluctuates periodically and gradually stabilises with the freeze-thaw cycles. Due to constraint by pipeline bearings, the maximum deformation occurs in the middle cross section of the buried pipelines, where the vertical displacement of the insulated pipeline is $26.9 \%$ less than that of the bare pipeline

(3) The stress accumulation caused by frost heave deformation seriously threatens the safe operation of the buried oil-gas pipelines. Compared with the bare pipeline, the maximum compression on the lower surface of the middle cross section of the insulated pipeline is reduced by $60.4 \%$

(4) In practical engineering, the ageing of materials will weaken the thermal insulation performance during the service years. Consequently, further studies on the new insulation materials and the optimal laying thickness are still necessary. Overall, the thermal insulation layer plays an active role in ensuring a safe and stable operation of the buried oil-gas pipelines in permafrost regions

\section{Data Availability}

The data used to support the findings of this study are included within the article.

\section{Conflicts of Interest}

The authors declare that they have no known competing financial interests or personal relationships that could have appeared to influence the work reported in this paper.

\section{Authors' Contributions}

Deren Liu was responsible for conceptualization, methodology, investigation, funding acquisition, writing-original draft, and writing-review and editing. Jiale Yang was responsible for methodology, software, validation, formal analysis, writing-original draft, and writing-review and editing. Xu Wang was responsible for conceptualization, validation, and funding acquisition. Junming Zhao was responsible for software, validation, and data curation. Shuochang $\mathrm{Xu}$ was responsible for data curation and visualization. Yongchun Zhao was responsible for supervision. All authors have read and agreed to the published version of the manuscript.

\section{Acknowledgments}

This work was supported by the National Natural Science Foundation of China (51268033), the Foundation of State Key Laboratory of Frozen Soil Engineering (SKLFSE201607), the Major Research Projects of PetroChina (XG11-2015-002), and the Technology Program of Gansu Province (1606RJYA240).

\section{References}

[1] O. B. Andersland and B. Landanyi, Frozen ground engineering, Wiley and ASCE American Society of Civil Engineering, New York, USA, 2nd edition, 2003.

[2] S. Gruber, "Derivation and analysis of a high-resolution estimate of global permafrost zonation," The Cryosphere, vol. 6, no. 1, pp. 221-233, 2012.

[3] F. E. Nelson, O. A. Anisimov, and N. I. Shiklomanov, "Climate change and hazard zonation in the circum-Arctic permafrost regions," Natural Hazards, vol. 26, no. 3, pp. 203-225, 2002.

[4] H. W. Li, Y. M. Lai, L. Z. Wang et al., "Review of the state of the art: interactions between a buried pipeline and frozen soil," Cold Regions Science and Technology, vol. 157, pp. 171-186, 2019.

[5] M. Yanhu, L. Guoyu, M. Wei, S. Zhengmin, Z. Zhiwei, and F. Wang, "Rapid permafrost thaw induced by heat loss from a buried warm-oil pipeline and a new mitigation measure combining seasonal air-cooled embankment and pipe insulation," Energy, vol. 203, p. 117919, 2020.

[6] S. L. Huang, M. T. Bray, S. Akagawa, and M. Fukuda, "Field investigation of soil heave by a large diameter chilled gas pipeline Experiment, Fairbanks, Alaska," Fairbanks, Alaska, Cold Regions Science and Technology, vol. 18, no. 1, pp. 2-34, 2004.

[7] K. Kim, W. Zhou, and S. L. Huang, "Frost heave predictions of buried chilled gas pipelines with the effect of permafrost," Cold Regions Science and Technology, vol. 53, no. 3, pp. 382-396, 2008.

[8] R. X. He and H. J. Jin, "Permafrost and cold-region environmental problems of the oil product pipeline from Golmud to Lhasa on the Qinghai-Tibet Plateau and their mitigation," Cold Regions Science and Technology, vol. 64, no. 3, pp. 279288, 2010.

[9] M. Burgess and D. Harry, "Norman Wells pipeline permafrost and terrain monitoring: geothermal and geomorphic observations, 1984-1987," Canadian Geotechnical Journal, vol. 27, no. 2, pp. 233-244, 1990.

[10] M. Burgess and S. Smith, "17 years of thaw penetration and surface settlement observations in permafrost terrain along the Norman Wells pipeline, Northwest Territories, Canada," 
in In Proceedings of the 8th International Permafrost Conference, pp. 107-112, Zürich, Switzerland, July 2003.

[11] J. M. Oswell, "Pipelines in permafrost: geotechnical issues and lessons," Canadian Geotechnical Journal, vol. 48, no. 9, pp. 1412-1431, 2011.

[12] S. R. Thompson and R. G. Tart, Driven, Pile Capacities in Warm Permafrost in Komi Republic, Russia. Cold Regions Engineering: The Cold Regions Infrastructure: An International Imperative for the 21st Century, ASCE, 1996.

[13] H. Long, S. Yu, H. Xiaoying, and W. Shengting, "Interactions between the pipeline and soils in permafrost regions: a review," Journal of Glaciology and Geocryology, vol. 39, no. 1, pp. 112122, 2017.

[14] H. J. Jin, "Design and construction of a large-diameter crude oil pipeline in Northeastern China: a special issue on permafrost pipeline," Cold Regions Science and Technology, vol. 64, no. 3, pp. 209-212, 2010.

[15] W. B. Yu, F. L. Han, W. B. Liu, and S. A. Harris, "Geohazards and thermal regime analysis of oil pipeline along the QinghaiTibet Plateau Engineering Corridor," Natural Hazards, vol. 83, no. 1, pp. 193-209, 2016.

[16] R. Shi, X. Wang, Z. Wen, and D. Li, "Estimates on thermal impact of gas-line and alleviating effect of countermeasures in patchy permafrost of northwestern China," Bulletin of Engineering Geology and the Environment, vol. 80, no. 3, pp. 26012616, 2021.

[17] H. Yuan, X. Zhen, W. Pengfei et al., "Field monitoring for frost-heaving and thawing-settlement of soil around gas pipelines in permafrost region," Journal of Engineering Geology, vol. 26, no. 4, pp. 1035-1042, 2018.

[18] S. Rui, X. Zhen, L. Deren et al., "Measurement and analysis of the ground temperature field with positive temperature gas pipeline in permafrost regions," Journal of Glaciology and Geocryology, vol. 41, no. 4, pp. 865-874, 2019.

[19] G. F. Xu, J. L. Qi, and H. J. Jin, "Model test study on influence of freezing and thawing on the crude oil pipeline in cold regions," Cold Regions Science and Technology., vol. 64, no. 3, pp. 262-270, 2010.

[20] Y. P. Wang, H. J. Jin, and G. Y. Li, "Investigation of the freezethaw states of foundation soils in permafrost areas along the China-Russia Crude Oil Pipeline (CRCOP) route using ground- penetrating radar (GPR)," Cold Regions Science and Technology., vol. 126, pp. 10-21, 2016.

[21] G. Y. Li, F. Wang, W. Ma et al., "Field observations of cooling performance of thermosyphons on permafrost under the China-Russia Crude Oil Pipeline," Applied Thermal Engineering, vol. 141, no. 6, pp. 688-696, 2018.

[22] F. Wang, G. Y. Li, W. Ma, Y. Mu, Z. Zhou, and Y. Mao, "Permafrost thawing along the China-Russia Crude Oil Pipeline and countermeasures: a case study in Jiagedaqi, Northeast China," Northeast China, Cold Regions Science and Technology, vol. 155, no. 8, pp. 308-313, 2018.

[23] L. C. Fang, B. Yu, J. F. Li, Y. Zhao, G. Yu, and W. Zhao, "Numerical analysis of frozen soil around the Mohe-Daqing crude oil pipeline with thermosyphons," Heat Transfer Engineering, vol. 39, no. 7-8, pp. 630-641, 2018.

[24] F. Wang, G. Y. Li, W. Ma et al., "Pipeline-permafrost interaction monitoring system along the China-Russia crude oil pipeline," Engineering Geology, vol. 254, pp. 113-125, 2019.

[25] M. T. Chai, G. Y. Li, W. Ma et al., "Assessment of freeze-thaw hazards and water features along the China-Russia crude oil pipeline in permafrost regions," Remote Sensing, vol. 12, no. 21, p. 3576, 2020.

[26] M. Serban, G. Y. Li, R. D. Serban et al., "Characteristics of the active-layer under the China-Russia Crude Oil pipeline," Journal of Mountain Science, vol. 18, no. 2, pp. 323-337, 2021.

[27] D. R. Liu, P. F. Wang, X. Wang, and Y. Hu, "The mechanism of pipe-trench thaw collapse of buried oil and gas pipelines in permafrost regions," Oil \& Gas Storage and Transportation, vol. 38, no. 7, pp. 788-792, 2019.

[28] L. Huang, Study on Mechanical Characteristics in the Process of Interaction between Pipe and Frozen Soil under Frost Heaving Conditions, [Ph.D. Thesis], University of Chinese Academy of Sciences, Beijing, China, 2019.

[29] C. Bonacina, G. Comini, A. Fasano, and M. Primicerio, "Numerical methods in phase-change problems," International Journal of Heat and Mass Transfer., vol. 16, no. 10, pp. 1825-1832, 1973.

[30] V. J. Lunardini, "Phase change around insulated buried pipes: quasi-steady method," Journal of Energy Resources Technology-Transactions of the ASME, vol. 103, no. 3, pp. 201-207, 1981.

[31] J. P. Zarling and D. J. Goering, "Performance of insulating systems for buried pipe," in In Proceedings of Regions Environmental Engineering, pp. 29-42, Fairbanks, AK, 1983.

[32] M. A. Hastaoglu and A. A. Hakin, "Freezing time predictions of buried pipes: a 3-D transient simulation," Chemical Engineering \& Technology, vol. 19, no. 3, pp. 243-248, 1996.

[33] L. Bronfenbrener and E. Korin, "Thawing and refreezing around a buried pipe," Chemical Engineering and Processingprocess Intensification, vol. 38, no. 3, pp. 239-247, 1999.

[34] S. S. He, W. B. Yu, W. G. Chen, Z. F. Yu, and H. J. Jin, "Nonlinear analysis of temperature fields around the buried oilpipeline in permafrost regions," Northeast China, Journal of Glaciology and Geocryology, vol. 30, pp. 0287-0295, 2012.

[35] H. W. Li, Y. M. Lai, and L. Li, "Impact of hydro-thermal behaviour around a buried pipeline in cold regions," Cold Regions Science and Technology, vol. 171, 2020.

[36] Y. T. Wang, Q. Gao, X. L. Zhu, M. Yu, and X. Zhao, "Experimental study on interaction between soil and ground heat exchange pipe at low temperature," Applied Thermal Engineering, vol. 60, no. 1-2, pp. 137-144, 2013.

[37] L. Huang, Y. Sheng, J. C. Wu, W. Cao, E. Peng, and X. Zhang, "Experimental study on mechanical interaction between buried pipe and soil during freezing," Cold Regions Science and Technology., vol. 178, p. 103129, 2020.

[38] W. D. An, Z. W. Wu, and W. Ma, Interaction among Temperature, Moisture, and Stress Fields in Frozen Soil, Lanzhou University Press Lanzhou, China, 1990.

[39] T. Wang, G. Q. Zhou, J. Z. Wang, and X. Zhao, "Stochastic analysis of uncertain thermal characteristic of foundation soils surrounding the crude oil pipeline in permafrost regions," Applied Thermal Engineering, vol. 99, pp. 591-598, 2016.

[40] Y. M. Lai, Q. S. Wang, F. J. Niu, and K. Zhang, “Three-dimensional nonlinear analysis for temperature characteristic of ventilated embankment in permafrost regions," Cold Regions Science and Technology, vol. 38, no. 2-3, pp. 165-184, 2004.

[41] Y. M. Lai, M. Y. Zhang, and S. Y. Li, Theory and Application of Cold Regions Engineering, Science Press, Beijing, 2009.

[42] X. X. Wei and Y. M. Lai, Principle and Application of Similarity Method, Lanzhou University Press, Lanzhou, 2001. 
[43] GB/T, Standard for geotechnical testing method, National Standard of the People's Republic of China GB/T 50123-2019, China Planning Press, Beijing, 2019.

[44] L. N. Zhu, "Study of the adherent layer on different types of ground in permafrost regions on the Qinghai-Xizang Plateau," Journal of Glaciology and Geocryology, vol. 10, no. 1, pp. 8-14, 1988.

[45] U. Berardi, "The impact of ageing and environmental conditions on the effective thermal conductivity of several foam materials," Energy, vol. 182, pp. 777-794, 2019.

[46] Z. C. Teng, X. Y. Liu, Y. Liu, Y. X. Zhao, K. Q. Liu, and Y. C. Teng, "Stress-strain assessments for buried oil pipelines under freeze-thaw cyclic conditions," Journal of Pressure Vessel Technology-Transactions of the ASME, vol. 143, no. 4, article 141803, 2021. 